\title{
History of the Scientific Study of the Tibeto-Burman Languages of North-East India
}

\author{
Satarupa Dattamajumdar*
}

(Received 25 April 2017; revised 19 October 2017)

\begin{abstract}
Linguistics or in other words the scientific study of languages in India is a traditional exercise which is about three thousand years old and occupied a central position of the scientific tradition from the very beginning. The tradition of the scientific study of the languages of the Indo-Aryan language family which are mainly spoken in India's North and North-Western part was brought to light with the emergence of the genealogical study of languages by Sir William Jones in the $18^{\text {th }} \mathrm{c}$. But the linguistic study of the Tibeto-Burman languages spoken in North-Eastern part of India is of a much later origin. According to the 2011 census there are 45486784 people inhabiting in the states of North-East India. They are essentially the speakers of the Tibeto-Burman group of languages along with the Austro-Asiatic and Indo-Aryan groups of languages. Though $1 \%$ of the total population of India is the speaker of the Tibeto-Burman group of languages (2001 census) the study of the language and society of this group of people has become essential from the point of view of the socio-political development of the country. But a composite historical account of the scientific enquiries of the Tibeto-Burman group of languages, a prerequisite criterion for the development of the region is yet to be attempted. Therefore, the present paper essentially concentrates on tracing the history of the scientific studies of the Tibeto-Burman languages spoken in North-East region of India.
\end{abstract}

Key words: Characterization, Chronology, Classification, Cognate, Development, Genetic, Linguistic, Morphology, North-East, Phonology, Stambaum, Syntactic, Tibeto-Burman, Tone

\section{INTRODUCTION}

Language was studied both from the literary and philosophical perspectives by the Indian linguists from early times. It was only in latter part of the eighteenth century when the genealogical relationship of Sanskrit with other European languages was established depending upon their resemblance at the morphophonological level by Sir William Jones in the $18^{\text {th }}$ century with his famous deliberation on 'comparative philology' in 1786.

The theoretical platform of comparative and historical linguistics was established in the earlier part of the nineteenth century. Until 1881 census, the need for recording the mother tongue of the citizens was not felt though in some provincial census like Bombay (1864), Madras Presidency (1871) and Bengal (1872) references can be had of some languages, their speakers' strength and location where they were spoken. In 1878 it was decided for the first time to record in the forthcoming census of the country, the mother tongue along with the place of birth of the people in order to decide on the nationality of the individual/community. The requirement was felt primarily to solve the issues of migration and to determine the nationality. So in the general report of the 1881 Census, list of languages along with the numerical strength of the speakers was listed (mostly from the secondary sources). By this time attention to the scientific enquiries of the

\footnotetext{
* 120 A, Dr. A. K. Pal Road, Behala, Kolkata-700034, West Bengal, Email: dattamajumdardrs@gmail.com
} 
languages of India was already in vogue, as evident in the philological works of Hodgson (1847), Campbell (1874), Hunter (1888), Robinson (1849), Skrefsrud (1889), Dalton (1872), Hoernle (1880), Beames (1872-79), Müller (1855) and others. Therefore, the awareness to understand the linguistic situation more systematically and strictly on philological grounds became inevitable at the all India level. The importance of recording linguistic affiliation and a systematic understanding of the Indian languages took the shape of a resolution in the Oriental Congress held at Vienna in 1886, urging the Government of India for a systematic survey of the languages of India. Thus it took hundred years (after the discovery of the genetic relationship of Sanskrit with other classical European languages by William Jones) to arrive at such a resolution for all India linguistic survey. The ground for G A Grierson's Linguistic Survey of India was prepared. By the time, 1891 Census could form a basis for philological researches by collecting the information on mother tongue and comparing them with the nomenclature of the different languages and language fields/areas of the country. So in 1894 the question of Linguistic Survey of India surfaced and was finally initiated in 1896 . The result of the survey was published in eleven volumes from 1903-1927. Regarding the complementary roles of Census report and the linguistic survey Nigam (1961, p. cLxi ) significantly observes,

\footnotetext{
"...it is only reasonable that the results of the census should be made to feed a scientific survey while the conclusions of such a survey should help in the calibration of census results and be guided in future census operation."
}

It is evident that the major philological studies of the nineteenth century concentrated on the languages of the Indo-Aryan language family which are mainly spoken in India's North and North-Western part, the socio-politically and socio-culturally dominant region of the subcontinent. But the linguistic study of the Tibeto-Burman languages of North-Eastern part of India did not receive the attention of the philologists in such a magnitude. The scientific study of the languages of this part of the subcontinent which started receiving attention from the latter part of the $19^{\text {th }} \mathrm{c}$. had its focus on grammatical and lexical studies. This was largely for the administrative purpose of the colonial administrators to understand the mother tongues of the region and their filial network, rather than purely philological enquiry. The colonial masters in order to control their subjects, the indigenous people of the land felt the necessity to learn the languages of the lesser known communities of North-East India and therefore, formulated grammatical sketches, words books and dictionaries on their own or with the help of the Christian missionaries. Therefore, the objective of the linguistic science practiced in the NorthEast region differed from those of the Indo-Aryan languages spoken in the North and North-Western part of the country.

Though the tradition of the scientific study of the languages of the Indo-Aryan language family which are mainly spoken in India's North and North-Western part was brought to light with the emergence of the genealogical study of languages by Sir William Jones in the $18^{\text {th }} \mathrm{c}$., the linguistic study of the Tibeto-Burman languages spoken in North-Eastern part of India is of a much later origin. The history of the science of language of this part of the subcontinent dates back to the last decade of the $18^{\text {th }} \mathrm{c}$ and started receiving attention from the later part of the $19^{\text {th }} \mathrm{c}$. The North- East Indian states which are widely known as seven sisters (Arunachal Pradesh, Assam, Manipur, Meghalaya, Mizoram, Nagaland and Tripura) and at present eight including Sikkim are strategically important from the point of view of society, politics, economy, language, culture and history. The area is essentially populated by the Indo-Mongoloid group of people (although people 
of Mongoloid origin are found in other parts of India also). In comparison to other states of India the North-East states of the country are linguistically and ethnically very highly heterogeneous. The indigenous people of NorthEast region are mainly the speakers of the TibetoBurman languages. The actual number of TibetoBurman languages spoken in this region is yet to be had due to lack of enough scientific investigations of these languages. The difficult mountainous terrain (except the Brahmaputra valley of Assam) also has hindered the accessibility of these areas and so the people and especially their languages are yet to be studied objectively. Due to scanty account of these languages and lack of scientific (or linguistic) enquiries, a fair idea is yet to be achieved about the speech varieties, whether a speech form is a language or a dialect (variation) of a language. However, according to 2001 census the total number of Tibeto-Burman languages spoken in India is sixty six. Out of these the number of Tibeto-Burman languages spoken in the NorthEast India is sixty two and the other four are spoken in the North-Western part of India.

The variation in the nomenclature of the languages also leads to a lot of confusion. Due to the annexation of the Assam valley by the British in 1826 , the colonial administrators having no knowledge at all about the speech communities came to administer the area. As a result names were imposed on these communities by the British administrators at different circumstances without actually knowing the names of these indigenous speech communities. Nineteenth and twentieth century witnessed the production of grammars by colonial administrators for these indigenous speech communities. In consensus to different scholars, practically speaking, the English people could never bring the land and the people of the hilly tracts of North-East India under its colonial administrative control. These administrators realized that the only means left to control the autochthones of the land is to understand their language. Thus such an endeavour of writing grammar and dictionary of the languages of these lesser known speech communities belonging to these remote areas gained ground. The Christian missionaries also played a very important role in developing a systematic method of writing grammar. All these grammars were mainly written in Latinate grammatical model. Although these works cannot be said to be the scientific enquiries of the languages as per the linguists' ideal, it served the purpose of literacy. These missionary activities rendered socio-religious and socio-economic support to these indigenous people of North-East India. In this connection it is important to share the observation of Burling (2003, p.172) that, as these grammars were developed in the traditional Latinate model, tone which is a major phonemic characteristic of these languages did not find its reflection in these grammatical studies. Such ignorance fetched a serious gap in understanding these languages at the pedagogical level for the younger generation of these speech communities. Comparative philological approach was attempted to study the languages of North-East India during latter part of nineteenth century and early part of the twentieth century.

The post-independence period witnessed efforts to write grammars and dictionaries which were linguistically sophisticated works undertaken by different Government agencies. Individual efforts are evident in producing primer, book of glossary, lexicon and graded-lessons for teachinglearning purpose of these less explored languages of North-East India. In spite of not being able to contribute at the level of comparative philology, such materials provide an overview of the language structure of these lesser known languages. Therefore, the comparative linguistic study of these languages had to depend upon only on the lists of words. Depending upon such a situation with scanty linguistic materials, scholars have attempted to characterize and classify the 
Tibeto-Burman languages at different points of time with some differences in sub-grouping. Burling (2003, p.174) thus points out the situation by stating,

\begin{abstract}
"At present, therefore, we have no choice but to rely primarily upon the lexicon for tentative judgments about which languages are genetically close and which are more distant. Languages which share the largest number of apparent cognates can be judged to be most loosely related but when reliable comparative phonology is lacking, as it generally is in Northeastern India, even judging cognate status often requires an uncomfortable amount of guess work."
\end{abstract}

However, the historical development of the scientific enquiries of the Tibeto-Burman languages spoken in North-East India in terms of classification and characterization has been attempted in the following sections.

\section{Characteristics and Classification of the Tibeto-Burman Languages}

The first work to capture the attention on Tibeto-Burman languages was Hodgson (1847) which dealt with the lists of vocabulary of the languages like Bodo, Koch and Dhimal spoken in North-East India. The scientific observation of the phonological and morphological structures of the languages spoken in this geographical area led Kuhn (1883) and Conrady (1896) to classify these languages into two broad groups - TibetoBurman and Siamese-Chinese as two major branches of the Sino-Tibetan language family. According to Shafer (1974) the Sino-Tibetan speaking area extends from the Great Wall of China to Malay Peninsula and from Kashmir to the Yellow sea. In order to understand the geographical stretch of the Tibeto-Burman languages Grierson (1927, p.53) sketches,

“...The most northern representative of the Tibeto-Himalayan branch is Tibetan, and the most southern representative of the Assam-Burmese Branch is Burmese.

\begin{abstract}
"Between them lie all the other TibetoBurman languages. The two extremes are connected along two distinct linguistic chains. The eastern chain consists of the Kachin and Lolo forms of speech, which connect Tibetan directly with Burmese. The western chain is at first a pair of chains each beginning in a different locality, but joining together lower down, like the letter Y. The joint chain then goes on and ends again in Burmese. The eastern limb of this $\mathrm{Y}$ begins with the miscellaneous forms of speech which make up the North Assam Branch and continues through dialects of the Naga Hills into those of the Bodo and KukiChin groups, where it meets the other, western limb. The latter begins with those dialects of Tibetan which have crossed the Himalayan watershed from the North and have occupied the southern face of that range. These also lead us into Bodo and Kuki-Chin. The joined eastern and western limbs then lead us, like Kachin and Lolo, into Burmese."
\end{abstract}

The distribution has been represented in the diagram presented in Fig. 1 below.

Hodgson was the first to observe the unity existing among the Tibeto-Burman languages and started publishing a number of papers from 1828 . A classification was also attempted by Max Müller in his Letter to Chevalier Bunsen on the classification of the Turanian Languages (Grierson, 1927, p.12). Müller classified these languages broadly into two groups - SubHimalayan or Gangetic and Lohitic. Lohitic comprises Burmese and the dialects of North Assam, Nāgā, Bodo, Kachin and Kuki-Chin groups. The scholars who contributed to TibetoBurman philology while dealing with the SinoTibetan comparative linguistics are Klaproth (1823), Müller (1855), Logan (1858), Forbes (1878), Grube (1881), Lacouperie (1887), Trombetti (1923), Przyluski (1924), Schmidt (1926), Li (1936-37) and others. Damant (1880) depending upon a list of around thirty vocabulary items (which he calls 'test words') attempted to 


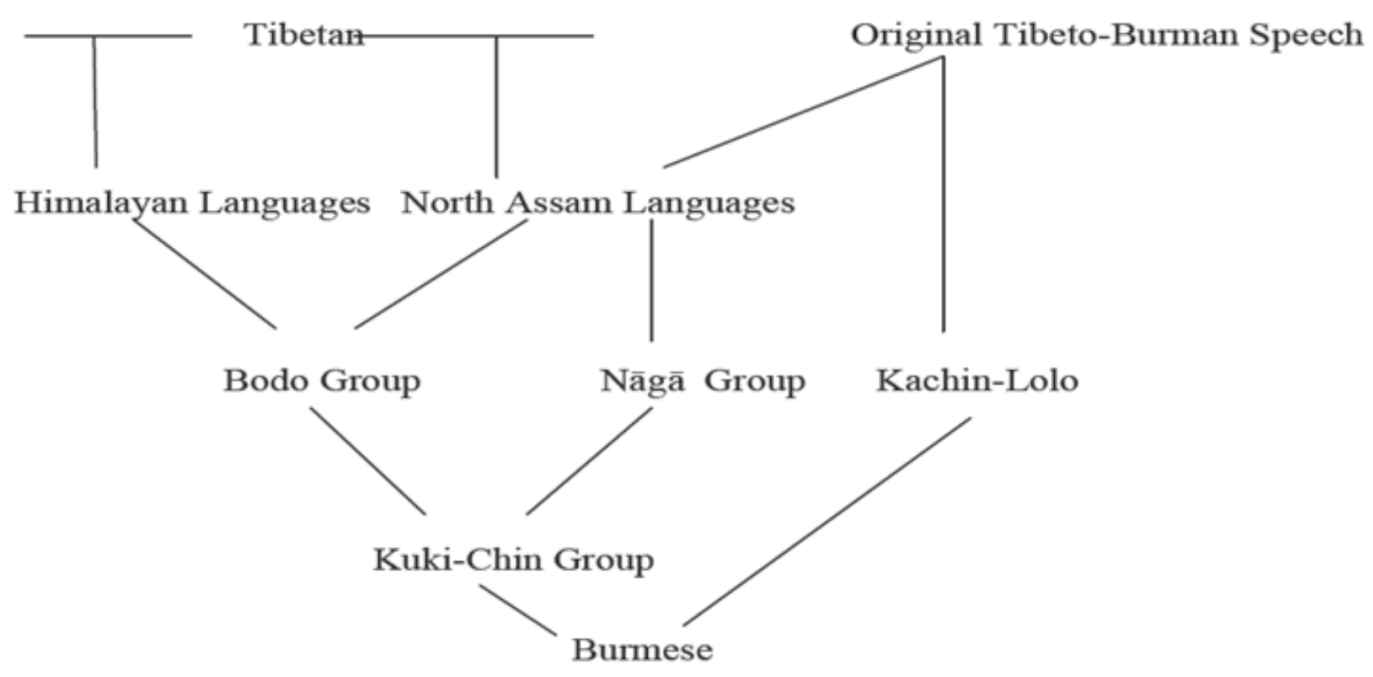

Fig. 1

classify the languages spoken in the area "...between Brahmaputra and Kaiendwen, Namtoni, or Ningthi, as it is indifferently called, the great western branch of the Irrawady" (Damant, 1880, p.228). The Tibeto-Burman group of languages is mainly classified and reclassified by Grierson (1903-1927), Shafer (1955), Shafer (1966-74), Benedict (1972), Bradley (1997, 2002) and Burling (2003). Marrison (1967) dealt with the classification of the Nāga languages of the Tibeto-Burman group. Broadly speaking the scholars agree to classify the Tibeto-Burman group of languages as one of the two groups or branches of Sino-Tibetan language family, the other being Siamese Chinese. But the rationale at the level of sub-grouping of these languages changed across the time with both similarities and differences amongst the scholars. The change of perspective observed in the major classifications and characterization of the Tibeto-Burman languages has been dealt with in the following.

\subsection{George Abraham Grierson (1903-1927)}

The early years of twentieth century witnessed characterization and classification of the Tibeto-Burman group of languages in the third volume of the Linguistic Survey of India by Grierson (1903-1927), an enquiry initiated in 1896 (already discussed in the earlier section). Depending upon the grammatical / linguistic characteristics of this group of languages and based on the comparative philological approach, the cognate relationship of these languages was established. Scientific study of the characteristics of the speech sounds, word structures and syntactic structures of these languages were attempted as far as possible.

The linguistic features of the TibetoBurman group of languages as emphasised by Grierson (1927) with example, are as follows:

(1) Has presence of a kind of inflexion developed by means of words which functions as particles; (2) developed vocabulary - separate words for the individual conceptions but lack of vocables for more general ideas; (3) avoided single use of the words like 'hand', 'father', 'mother', etc. These are used with the possessive pronominal form only like, Thado $k \bar{a}-p \bar{a}$ 'my father', $\bar{a}-k h \bar{u} t$ 'his hand' but are never used individually like $p \bar{a}$, $k h \bar{u} t$, etc.; (4) used generic particles with numerals (attested in Bodo, Kuki-Chin groups and also in Burmese) in order to indicate the special class of objects to which the qualified word belongs. Burmese palong s'ay-li 'bottle ten-round things' or 'ten bottles'; (5) used a word as noun, as an 
adjective and as a verb. That is, presence of "indefinite bases of which the radical meaning is still so free and general that they can be used either as subjects or as predicates, and, therefore, as nouns, as adjectives or as verbs at will" (Grierson, 1927, p.6); (6) absence of grammatical gender. The natural gender of animate beings is distinguished by different words for male and female; (7) the number is deduced from the context or "is marked by adding numerals or words meaning 'many', 'all', 'several', and so forth" (Grierson, 1927, p.6); (8) lacked proper declension system. Words are suffixed and functions as post positions to indicate different relation in time and space. These words which were originally lexical items behave like a particle (as they are separable) and are added to the last of a number of connected words. For example, these particles are added to an adjective that follows a noun, but these particles are not added to the qualified noun; (9) the genitive being unmarked, the noun which is governed is put before the governing noun. Sometimes an element is also added which looks like suffix in order to indicate genitive. These genitive suffixes in many Tibeto-Burman speeches are derived from demonstrative pronouns; (10) adjectives following or preceding the qualified noun forms; (11) absence of comparative and superlative forms. Postpositions are added to the compared noun to mark the 'relative' meaning of the adjective; (12) the numeral system is decimal in nature. Pre fixation of 'one', 'two', etc. to 'ten', etc. is the rule of formation of higher numbers (attested in Tibetan, Chinese, Burmese, Kachin, Meitei, Sho, Mikir, etc.). However, the multiplier is suffixed in case of the varieties belonging to Bodo, Nāgā and Kuki-Chin groups of languages; (13) formation of higher numbers counted in twenties (not in tens) attested in many Himalayan languages (e.g., Kanāwari nish nizzāū sai 'two twenties ten' meaning 'fifty'). However, this is traced to be a non Tibeto-Burman element; (14) used different forms of pronouns for 'we' - in some cases excluding and in some other cases including the person who is addressed (attested in Garo); (15) absence of relative pronominal forms. Use of participle is found to indicate the meaning. (e.g., Burmese pyu-thi th $\bar{u}$ 'doing man' meaning 'the man who does'); (16) the verb forms which are actually nouns and are not capable of inflexion in person, number or gender. (Those found with conjugational form are due to the influence of other forms of speech); (17) use of tenses loose. In order to emphasize on time, words are added to indicate the occurrence of the fact/event; (18) formation of negative verbs by prefixing a negative particle to the verbal noun; (19) the usual word order is subject-object-verb. The existing inconsistency in this regard and comparison with Chinese and Siamese reveal that fixed word order is a modern development of the Tibeto-Burman languages; (20) the development of the system of different tones has been traced to be a consequence of dropping of the old prefixes at an earlier date. The languages where such a development is absent is "probably due to the more thoroughgoing preservation of the old prefixes" (Grierson, 1927, p.10) and also due to the influence of other indigenous languages of the land.

Keeping in view the characteristic features of the Tibeto-Burman languages Grierson (1927) traces the filial linkage of these languages by cross linking the geographical location and the linguistic features. The major contentions of Grierson's classification of Tibeto-Burman sub-family are enumerated below:

(1) The old form attested in Tibetan (of Central Tibet) exhibits extensive use of prefixes which later lost its existence as a separate syllable and reduced to a consonant. The soft consonants (e.g., $y / d z$ ) are well preserved in the initial positions which became hard with aspiration in the modern speech form. With this the system of tone developed in the speech form of Central Tibet. (2) In the western part of the Tibeto-Burman area, the prefixes developed and were preserved to a great extent. The soft initials became aspirated and 
hardened. But development of tones is not evident in these speech varieties. (3) The development of the eastern speech varieties resembles the western ones. (4) Some varieties of Tibetan (spoken in the Chinese province of Ssechuan) attest the retention of full syllables of the prefixes. In this regard these speech varieties connect the Tibetan with the varieties of the Kachin, Nāgā and Bodo groups. (5) The speech varieties of Kachin are found to agree with classical Tibetan in respect to the preservation of old soft initials (exhibiting a strong tendency of aspiration) and preservation of old prefixes (where causals are formed by prefixes). Kachin also resembles with the speech varieties of Central Tibet in respect to the system of tones. (6) As Kachin is spoken in the neighbourhood of Burmese in the southern part, the speeches agree in the use of prefixes and suffixes and with the developed system of verbal particles. Thus philologically Kachin is considered as a link between Tibetan and Burmese. (7) The speech varieties of Nāgā and Kuki-Chin groups which are neighbours of Kachin in the west share many characteristic features of Kachin. The extensive use of prefix $g a$ and $k a$ is shared by Kachin and Nāgā whereas, Kuki-Chin strikingly resembles with Kachin at the level of vocabulary and suffixation. (8) The Nāgā group of languages is more closely related to Tibetan than it is to Burmese. They share elaborate system of tones, negative verbs (formed with negative prefixation), etc. Therefore, these varieties are classed together under the Central Nāgā sub-group. (9) The Central Nāgā sub-group differs from other varieties of Nāgā group. The other Nāgā varieties use negative suffix like the languages of Bodo and Kuki-Chin groups. Thus in the south and in the west the Nāgā varieties are found connected with the Bodo and Kuki-Chin languages by means of other intermediate speech varieties. (10) The different speech varieties which have been put together as the North-Assam group connect the Tibetan with the varieties of the Bodo-group. (11) There is a long stretch of language varieties spoken in the central and lower Himalayas, which are grouped under Himalayan languages. In spite of differences amongst the varieties, these speech varieties form a link between Tibetan and the varieties of Bodo and Kuki-Chin groups. (12) The varieties of the Bodo group agree with Tibetan in respect to the preservation of consonants (soft) in the initial position and in the formation of causal verbs by adding prefixes. (13) Formation of causal verbs by adding prefixes is a shared feature of Bodo, Nāgā and Kuki-Chin speech varieties. (14) KukiChin speech varieties are observed to form the "last link in the chain connecting Tibetan with Burmese, the southernmost Tibeto-Burman language" (Grierson, 1927, p.10).

Depending upon the above observation (though mainly at the morpho-syntactic level) Grierson (1927, p.12) has tried to link the geographical distribution of the Tibeto-Burman speakers and the linguistic characteristics of the Tibeto-Burman languages. He states,

"Tibetan and Burmese, the northernmost
and southernmost Tibeto-Burman
languages, are connected by means of two
different chains of dialects. The eastern
consists of various Kachin dialects, the
western has a double beginning in the
north, which unites towards the south. In
the first place we find the dialects of the
North-Assam group merging into the
Nāgā, and further into the Bodo and Kuki-
Chin forms of speech, and in the second
place, we can also trace a line from
Tibetan, through the Himalayan
languages, into Bodo and further into
Kuki-Chin. Those latter dialects then
gradually merge into Burmese."
(illustrated in Table-1)

A broad classification of the TibetoBurman group of languages which belong to the Sino- Tibetan language family provided by Grierson (in his Linguistic Survey of India) and represented in Chatterji (1951, p.24) is presented in Fig. 2. 
A detailed classification of the TibetoBurman group of languages provided by Grierson (in his Linguistic Survey of India) and represented in Chatterji (1951, p.25) is given in Fig. 3.

However, due to the split of different speech forms at a much earlier date followed by numerous 'crossings' and 'intercrossings' with other speech forms across the time period, Grierson observed the impossibility of classifying the Tibeto-Burman speeches with satisfaction. Therefore, the classification provided in the Survey is claimed to be a provisional one.

\subsection{Robert Shafer (1966-1974)}

The second half of the twentieth century witnessed a different perspective in dealing with the classification of the Sino-Tibetan languages from that of the early part of the twentieth century. The essential point of development was the shift in the parameter of classification of these languages from morphology to morphophonology. This is evident in the contribution of Robert Shafer in 1974. The major literary languages of the Sino-Tibetan family spoken in the belt 'extending from the Great Wall of China to the Malay Peninsula and from Kashmir to the yellow sea' have been considered as the focal point of the treatment. The major literary languages which have been made the criteria of the broad divisions are Chinese, Siamese, Burmese and Tibetan. The transmission of language through culture across the political borders did not escape his notice. This influenced the vocabulary and the structures of the languages. Shafer (1974, p.1) states,
"Thus the Chinese transmitted their culture to Japan, Korea, the Manchus, Mongols, and Central Asia. The Tibetans carried the culture of India to the Chinese, the Turks, the "Tokharians" and probably to the Khotani Sakas. No doubt much of

\section{Sino-Tibetan (or Tibeto-Chinese)}

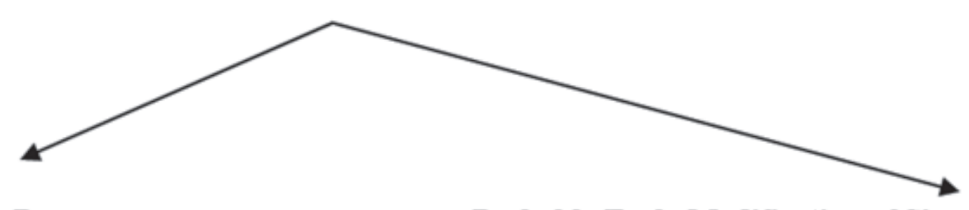

Sino Tibetan Proper

Probably Early Modification of Sino-Tibetan

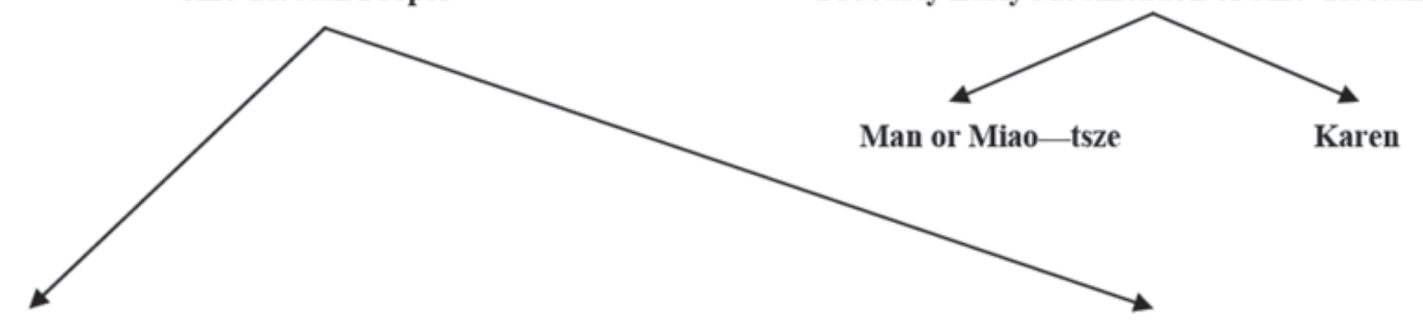

(II)Tibeto-Burman

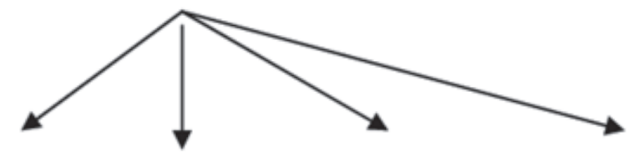

(a) Tibetan

(b)

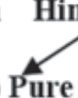

Himalayan

(d) (c) Modified

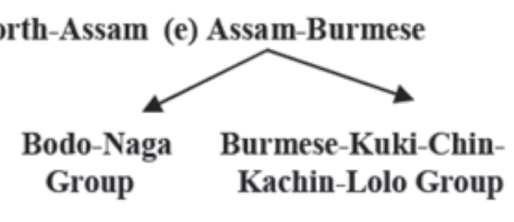

(II) Siamese-Chinese

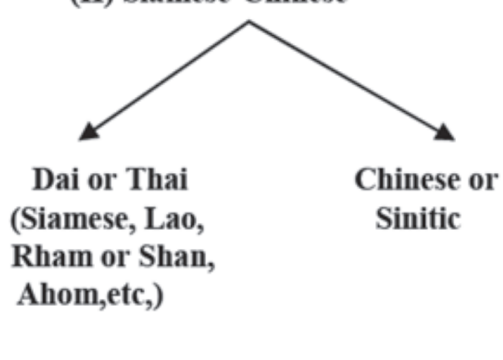

Fig. 2 


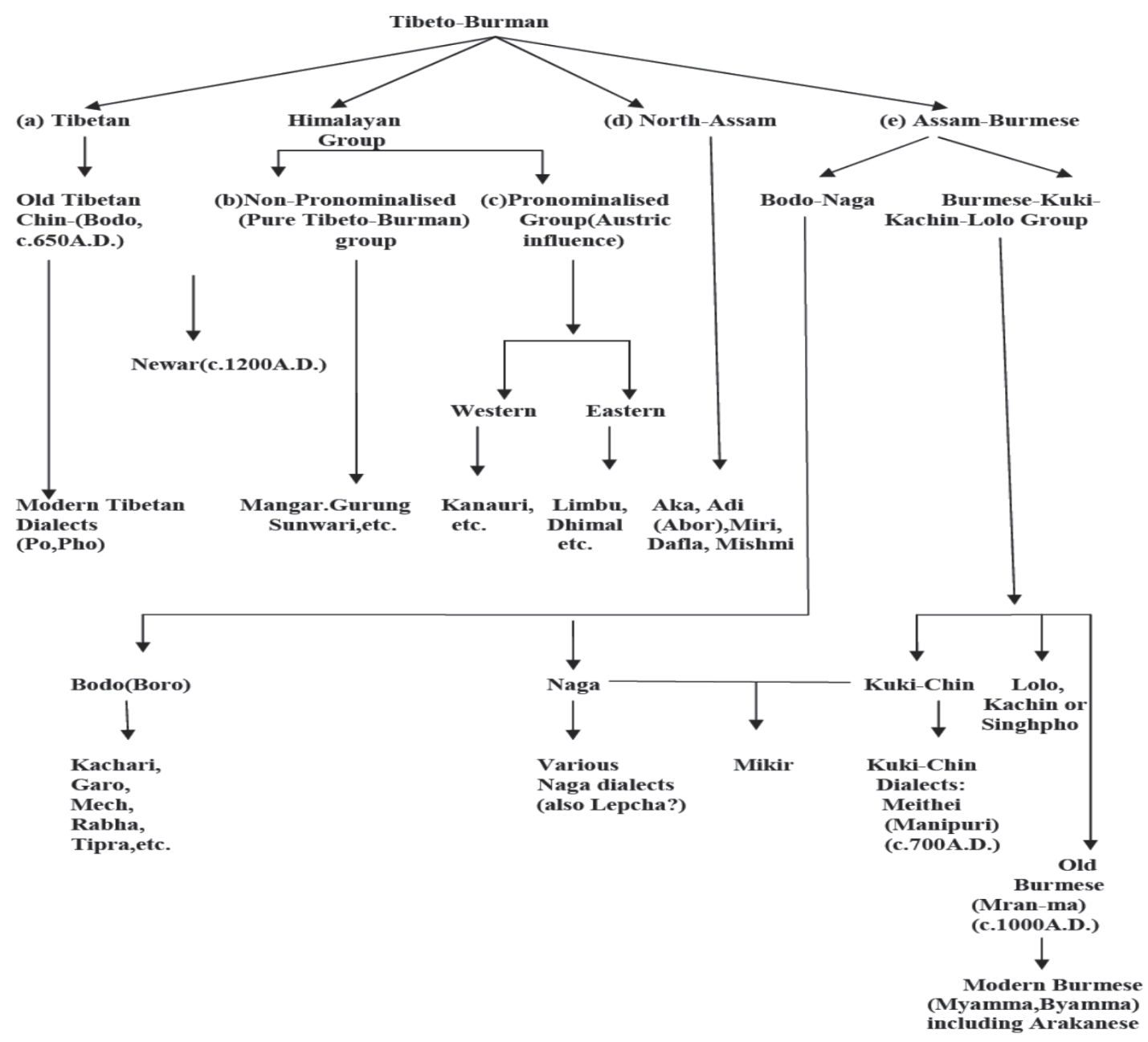

Fig. 3

the Indic culture was relayed to Cambodia, the Mon, the Annamese, and to some extent to the Javanese, by passing first through the hands of the Pyu, the Burmese, the Karens, the Dais (Thai), and other Sino-Tibetan peoples."

Regarding the linguistic characteristics of the Tibeto-Burman languages, phonetic rules were formulated by postulating the forms of the protostage and pointing out the morpho-phonological deviations of the languages at the individual levels. Keeping in view the major literary languages Shafer proposes a six point division in the classification of the Sino-Tibetan language family. The major division is presented in the following Fig. 4.
Each of the divisions has been further classified and elaborated in Appendix -1.

The point of departure being radically different from the earlier (also later) classification of the Sino-Tibetan languages, the classification exhibits more reliance on the morphophonological principle than on geographical aspect, though geographical (rather directional) factors dominate as a criterion at the subclassificatory level. Unlike the classification provided in Grierson (1903) the Tibetan and Burmic groups have been treated differently and not in compounded form.

The Bodo group which Shafer calls Baric has been treated differently as a main division of 


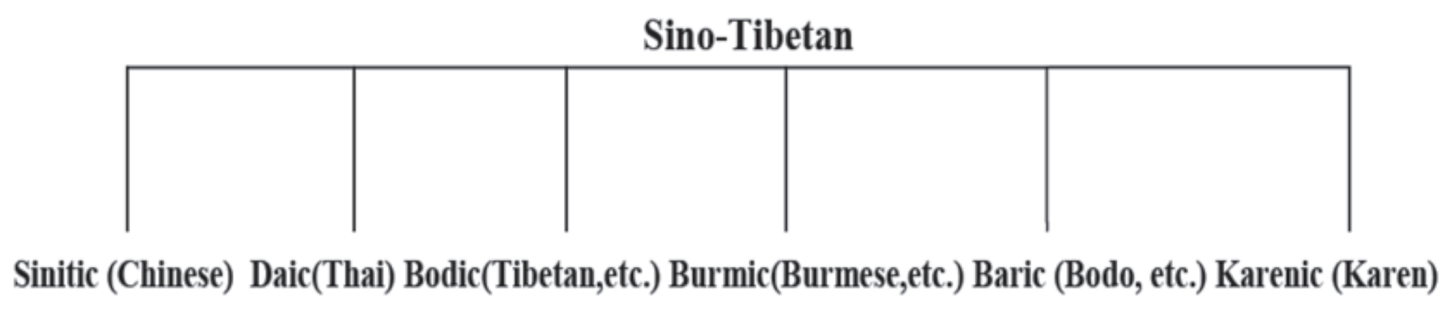

Fig. 4

Sino-Tibetan and not as compounded sub-group with Nāgā under Assam-Burmese sub-group of Tibeto-Burman evident in Grierson (1908). The Nagish section has been dealt with as a sub-section separately under Baric division. In this connection Shafer (1974, p.440) states,

\begin{abstract}
"Because of the considerable divergence of the Baric vocabulary from that of better known Tibeto-Burmic languages and because of limited materials available on Baric, the primary aim has been to note phonetic equations within Baric, secondarily to connect these equations with the corresponding phonemes in other Tibeto-Burmic languages when possible."
\end{abstract}

However, the Baric division will be treated in detail elsewhere while dealing with the linguistic historiography of the Bodo group of languages.

\subsection{Paul K Benedict (1972)}

A difference in perspective is also evident in the characterization and classification of the Tibeto-Burman group of languages, Sino-Tibetan: A Conspectus by Paul K Benedict in 1972. The investigation was accomplished and was drafted almost twenty five years back until James A Matisoff of Columbia University took initiative to enable the work see the light of the day. As a contributing editor of the conspectus Matisoff provides supplementary notes based on his own studies on Lahu and other related languages of the stalk. The Tibeto-Burman group is classified as a sub-group under Sino-Tibetan language family. Depending upon a series of monosyllabic roots three primary groups are classified under Sino-Tibetan. They are - Tibeto-Burman, Karen and Chinese where Tibeto-Burman and Karen constitute a super family known as Tibeto-Karen. Based on the lexical consideration, it is observed that the agreement between Karen and TibetoBurman is predominant. Regarding the nature of affiliation Benedict (1972, p.2) states,

\footnotetext{
"The relationship between Tibeto-Karen and Chinese is a distant one, comparable with that between Semitic and Hamitic, or between Altaic and Uralic-Karen, on the other hand, stands in relation to Tibeto-Burman much as Hittite stands in relation to Indo-European, i.e., TibetoKaren is on the same taxonomic level as Indo-Hittite."
}

Observing the syntactic constructions, where Chinese and Karen follow verb+object order and Tibeto-Burman attest object+verb order, it is suggested that the Tibeto-Burman is more archaic in nature than Chinese and Karen. This might be the influence of the contiguous languages like Thai, Miao-Yao and Mon-Khmer.

Benedict (1972, p.5) illustrates the genetic relationship of the Tibeto-Burman languages by classifying the group into seven primary divisions which is presented below.

(1) Tibetan-Kanauri (Bodish-Himalayish); perhaps also Dzorgai, Lepcha, and Magari (2) Bahing-Vayu (Kiranti); perhaps also Newari (3) Abor-Miri-Dafla (Mirish); perhaps also Aka, Digaro, Miju, and Dhimal (4) Kachin; perhaps also Kadu-Andro-Sengmai (Luish) and Taman (5) Burmese-Lolo (Burmish); perhaps also Nung (6) Bodo-Garo (Barish); perhaps also Konyak and Chairel (7) Kuki-Nāgā (Kukish); perhaps also Mikir, Meithei, and Mru. 
In the conspectus it is significantly noted that Kachin exists "at the linguistic 'crossroads' of Tibeto-Burman, thus occupying a linguistic position comparable with its geographical setting (Northern Burma)" (Benedict, 1972, p.5). It has been observed that both at the lexical and morphological levels, Kachin co-ordinates with the northern languages like Tibetan, Bahing, etc., the southern languages like Burmese, Bodo, Lushei, etc., Nung, Burmese-Lolo on the east and Konyak and Bodo-Garo languages on the west. The interrelationship existing amongst these diverse languages is represented in Fig. 5 (Benedict, 1972, p.6) below.

Benedict characterizes the Tibeto-Burman group of languages both from the phonological and morphological view points. The major languages which have been exemplified in order to establish the speech sounds of the TibetoBurman group are Tibetan, Kanauri, Gyarung, Garo, Kachin, Lushei and Burmese. Other languages which have also been considered are Bodo, Nung, Meithei, Maring, Dimasa, Limbu, Miju, Mikir, Magari, Lepcha, Kadu, Bunan,
Digaro and Bahing. The salient features put forth by Benedict (1972) are discussed below.

(1) The phonemic and morphemic analysis postulates the existence of sixteen consonant phonemes in general for the Tibeto-Burman group. These are - Velar: ${ }^{*} \mathrm{~g}{ }^{*} \mathrm{k} * \eta{ }^{*} \mathrm{~h}$ Dental: $*_{\mathrm{d}} *_{\mathrm{t}} *_{\mathrm{n}} *_{\mathrm{s}}$ $*_{\mathrm{z}}{ }^{*} \mathrm{r}{ }^{*} 1$ Labial: ${ }^{*} \mathrm{~b}{ }^{*} \mathrm{p}{ }^{*} \mathrm{~m}$ Semivowels: ${ }^{*} \mathrm{w}{ }^{*} \mathrm{y}(2)$ Existence of stop consonants (surds/ voiceless) and nasals in the root final position. (3) Existence of final consonants like $-\mathrm{r},-1,-\mathrm{s},-\mathrm{w}$ and $-\mathrm{y}$ and retention of $-\mathrm{r}$ and -1 (in Tibetan, Kanauri, Lepcha, Nung, Lushei, Dimasa, Moshang) (4) Maintenance of $-\mathrm{s}$ in the root final positions (evident in Tibetan, Gyarung and Kanauri). (5) Occurrence of all the sixteen consonant phonemes in the initial position (either single or in cluster). (6) The voiced and unvoiced stops are in contrastive distribution (7) Aspiration is a subphonemic feature. (8) Unvoiced stops are aspirated in the initial positions and unaspirated after prefixes. (9) Tendency of surdization (in other words devoicing) of initial sonant stops (generally preserved in Tibetan, Kanauri, Bahing, Miri and other northern languages). (10) Shift from surd to

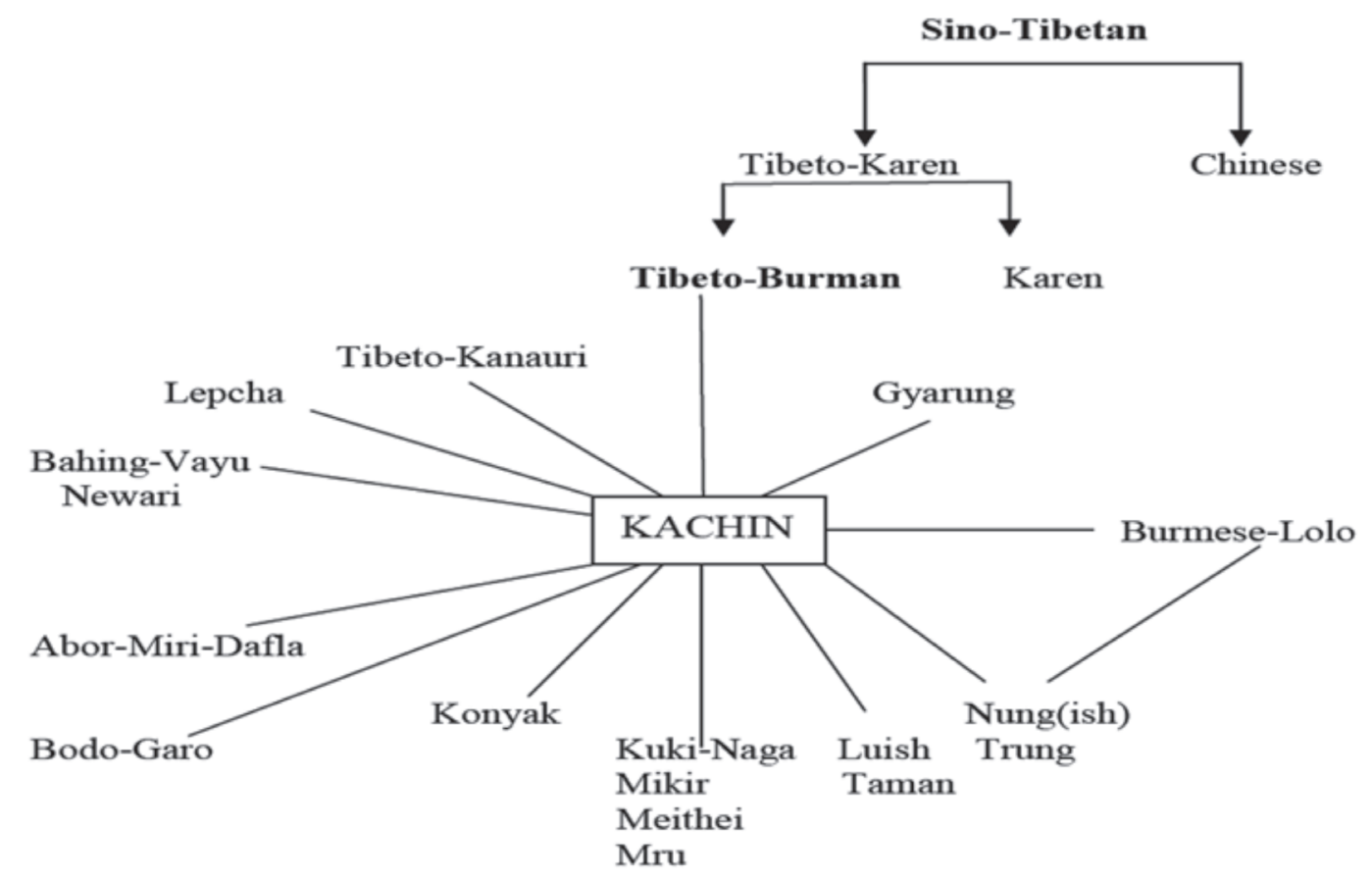

Fig. 5 
sonant is also evident in some cases (especially in Garo). (11) Palatalization of *t- before $-\mathrm{i}$ (evident in Garo-Bodo). (12) Contrast between voiced and unvoiced affricates (aspiration is of secondary significance). (13) Shifts of $*_{\mathrm{ts}^{-}}>\mathrm{s}$ and $*_{\mathrm{s}-}>\mathrm{t}(\mathrm{h})$ are characteristic features of the Tibeto-Burman languages (especially Garo-Bodo and Kuki-Nāgā). (14) Nasals in the initial positions are well preserved in Tibeto-Burman. (15) *r- and *1- in the initial positions are well maintained though occasionally shifts are also evident, i.e., *1- >r-. (16) Initial *h- is rare in Tibeto-Burman. It can only be reconstructed for a few restricted roots and loan words (e.g., Garo has a few words which attest h- in the initial position). (17) Existence of semivowel $* y-$ in the initial positions (shift from *y- to z- is evident in Lushai and dź tś- in Garo and Mikir). (18) Existence of the semivowel ${ }^{*} \mathrm{~W}$ in the initial position (reconstructed depending upon the southern Tibeto-Burman languages). (19) Prefixed ${ }^{*}$ s- aspirates (unvoices) nasals and liquids in the initial position in many Tibeto-Burman languages like Burmese and Lushai/Mizo and also in Magari, Digaro and Dhimal (though not a regular feature). (20) Tibeto-Burman attests glottalisation. Vowels in the initial position are preglottalised in the Tibeto-Burman roots. (21) Existence of consonant clusters of two types(a)Stop or nasal +liquid $(\mathrm{r} \sim 1)$ and (b) Consonant + semivowel $(\mathrm{w} \sim \mathrm{y})(22)$ Tibeto-Burman ${ }^{*} \mathrm{~W}$ occurs in the medial position only before $a$ and $i$ (attested in Burmese and Lushei regularly, and other languages with less regularity). (23) The Tibeto-Burman vowel system consists of five phonemes: /a, o, $u, i, e /$. They appear in medial and final positions. Occurrence of pure vowel in final position is rare (except $a$ ). (24) Combinations of vowel $+w$ or $y$ characterize the Tibeto-Burman system. "The low vowel $a$ (short or long) combines freely with $-w$ or $-y$, while the mid-high back vowel $o$ combines with $-w$ (rarely with $-y$ ) and the mid-high front vowel $e$ combines with $-y$ (very rarely with $-w$ )" (Benedict, 1972, p.62). (25) Occurrence of tone is an important characteristic feature of the Tibeto-Burman languages. (Scanty data hindered analysis). (26) Tibeto-Burman exhibits the features of isolating languages "....with roots of simple monosyllabic type, normally prefixing but occasionally suffixing" (Benedict, 1972, p.92). (27) The derivation of nouns from verbs, through prefixation or suffixation is a process of Tibeto-Burman morphology. But the reverse type of derivation is very rare. (28) The Tibeto-Burman numeral system is of decimal type. It also includes vigesimal unit along with specific distinctive roots. (29)The invariable syntactic rule of Tibeto-Burman is, the verb is placed at the end of the sentence followed only by suffixed elements or sentence-final particles. (30) Usually the object in a sentence immediately precedes the verb and comes after the subject. (31) "The concepts of 'subject', 'object', 'indirect object', 'instrumentality' and the like are reinforced or expressed in modern TB languages by morphemes suffixed to nouns"(Benedict, 1972, p.95). (32) The alteration of root initial consonants is a general morphological process assigned to Proto TibetoBurman. The fundamental contrast between intransitives with sonant initials and between transitives with surd initials (attested in Tibetan, Kiranti, Bahing, Vayu and Bodo-Garo) is an inherited Tibeto-Burman feature.

\subsection{David Bradley (1997)}

The Tibeto-Burman group of languages has been classified by Bradley (1997) into four major divisions. The classification is primarily based on geographical criteria. The major division is provided in Fig. 6.

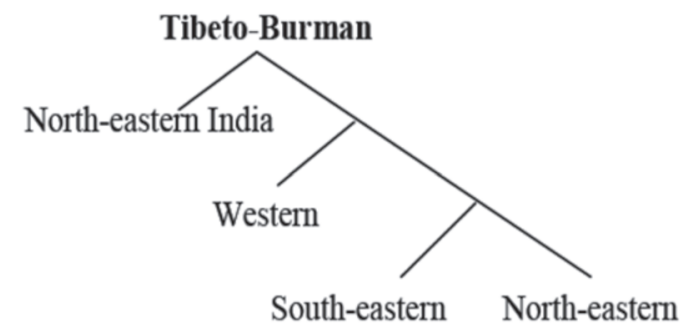

Fig. 6 
The languages which Bradley considers under the 'North-eastern India' are the languages which are included by Shafer (1974) in his Baric group, by Benedict (1972) in his Bodo-GaroKonyak group. These languages are considered under the name 'Sal' group (a distinct etymon for 'Sun') along with Jinghpaw (Kachin and Sak or Luish group) by Burling (1983). The languages considered under western group correspond with Shafer's 'Bodic' group and Tibetan/Kanauri along with Himalayan in Benedict's classification.

Keeping in view North-East India as the focal point of present investigation, the North-East India group or 'Sal' group (used by Burling 1983) has been classified by Bradley (1997, p.20). The classification is presented in Fig. 7.

Here it is pertinent to mention the justification of the geographical distribution behind the classification provided by Bradley. He (1997, p.20-21) states, "All these languages are SOV, with
substantial prefix and suffix morphology.
The Luish or Sak group is scattered and
moribund but formerly covered a much
wider area;... Jinghpaw is the core group
in the Kachin cultural system, which also
includes several Burmish and a few other
groups which fit elsewhere linguistically.
Baric includes Bodo (Bodo, Bara, Båra
[boro], or 'plains Kachari'), formerly the
main language of the upper Brahmaputra
valley in north-eastern India, with very
closely related languages such as
Dimas(h)a('hills Kachari'), Kokborok
(Tripuri), Lalung and so on covering the
plains and low hill areas to the south, and
fairly closely related Garo in the hills of
South-west; also the 'Koch' languages
such as Atong, Rabha, Wanang and so on generally in the plains to the west, with the still rather closely related Northern Naga languages of northern Nagaland, Tirap district of Arunachal Pradesh, and adjacent areas of Burma to the east. Jinghpaw is spoken in a large area immediately to the south-east of the latter, with the Sak group scattered (in an area mainly inhabited by speakers of other TB languages) to the South.”

\subsection{Graham Thurgood (2003) and Robins Burling (2003)}

The beginning of the twenty first century witnessed a re-classification of the Tibeto-Burman languages both by Graham Thurgood and Robins Burling. As the classification of the two scholars resembles and were published in the same volume the two contributions have been dealt with together in this paper. Thurgood (2003) classified the SinoTibetan languages based on "...full reconstruction of the lexicon and with description of the corresponding sound changes..." and "...backed by shared morphological innovations..." (Thurgood, 2003, p.5). The major sub-grouping of the Tibeto-Burman group provided by Thurgood (2003) is presented in the following.

(1) Lolo-Burmese branch (2) The Bodic branch (=Tibetan) (3)The 'Sal' languages [BodoKonyak-Jinghpaw] (4) The Kuki-Naga branch (5)The Rung branch (6)The Karenic branch (7) Other small subgroups (Tani) (8) Unsubgrouped languages (Pyu, Naxi, Tujia, Bai)

The detailed sub grouping of the TibetoBurman group is evident in Burling (2003) which has been dealt with in the following.

Depending mainly upon the word lists and sentence lists (though scanty) available in the

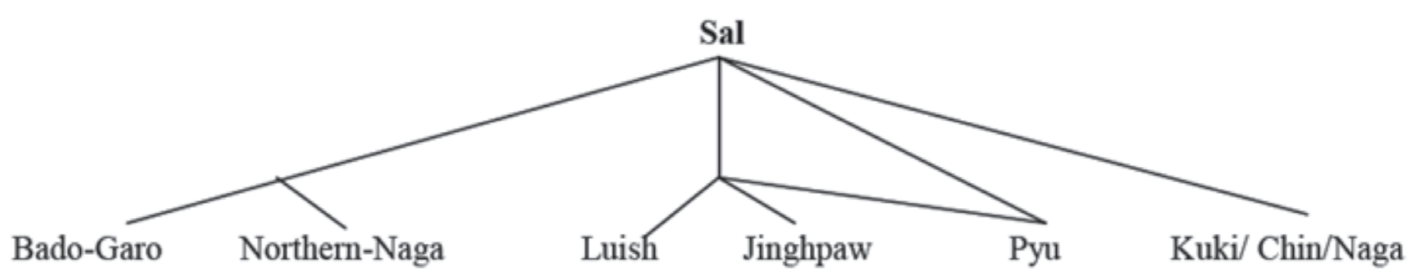

Fig. 7 
existing literature, Burling (2003) provides us with a brief typological sketch of the Tibeto-Burman languages spoken in the North-East region of India. While attempting for a relatively reliable classification of the Tibeto-Burman languages of North-East India Burling (2003) observes fourteen separate branches of Tibeto-Burman languages. Burling(2003) classifies the Tibeto-Burman languages of North-East India depending upon three major regions - the Central Area (to which belongs the Bodo-Konyak-Jinghpaw sub group); the Northern Area (to which belongs TshanglaTakpa, Sherdukpen, Bugun/Khoa, Sulung, Lishpa; Hruish; Tani group; Idu-Digaru; Miju) and Eastern border Area (to which belong Ao group; AngamiPochuri group; Zeme group; Tangkhul group; Karbi(Mikir) group; Meithei and Mizo-Kuki-Chin (Kukish) group). The Tibeto-Burman languages of North-East India which Burling (1983) calls 'Sal' languages have been classified under the term 'Bodo-Konyak-Jinghpaw' group (2003) which practically and conveniently divides the entire geographical North-East region into two parts: the northern part (primarily Arunachal Pradesh) and the eastern part, that is, the region of more than one North-East state lying along the border of Myanmar. The plausible Stambaum of the NorthEastern languages belonging to the central area proposed by Burling (2003, p.175) is presented in Fig. 8.

From the classification of Bodo-Koch branch provided by Burling (2003) it is observed that the Garo language is closer to Bodo. But Koch is considered to be less close and so it is classified as a Bodo-Koch subgroup.

Burling (2003) also mentions that in the earlier classification Garo is found to be closer to Koch. He also tries to trace the reason behind such observations. The mutual intelligibility of A'tong and Ruga with Garo (due to their physical proximity) might be the reason for such observation which has been formalized by Benedict (1972, p.6 -7) by using the term 'Garo A' for A'tong and Ruga and 'Garo B' for the proper Garo language. Benedict also observed that Rabha (a language spoken in the north and north-west of the Garo hills area) is closer to A'tong and Ruga and therefore, considered Rabha under 'Garo A' subgroup. Thus to consider A'tong and Ruga as languages of 'Garo A' is based on ethnic criteria whereas, the rationale to consider Rabha in the same group of A'tong and Ruga is based on the linguistic criteria (of closeness). Burling states that linguistically Rabha, A'tong Ruga and Koch (along with its dialects like Tintikiya Koch, Wanang Koch

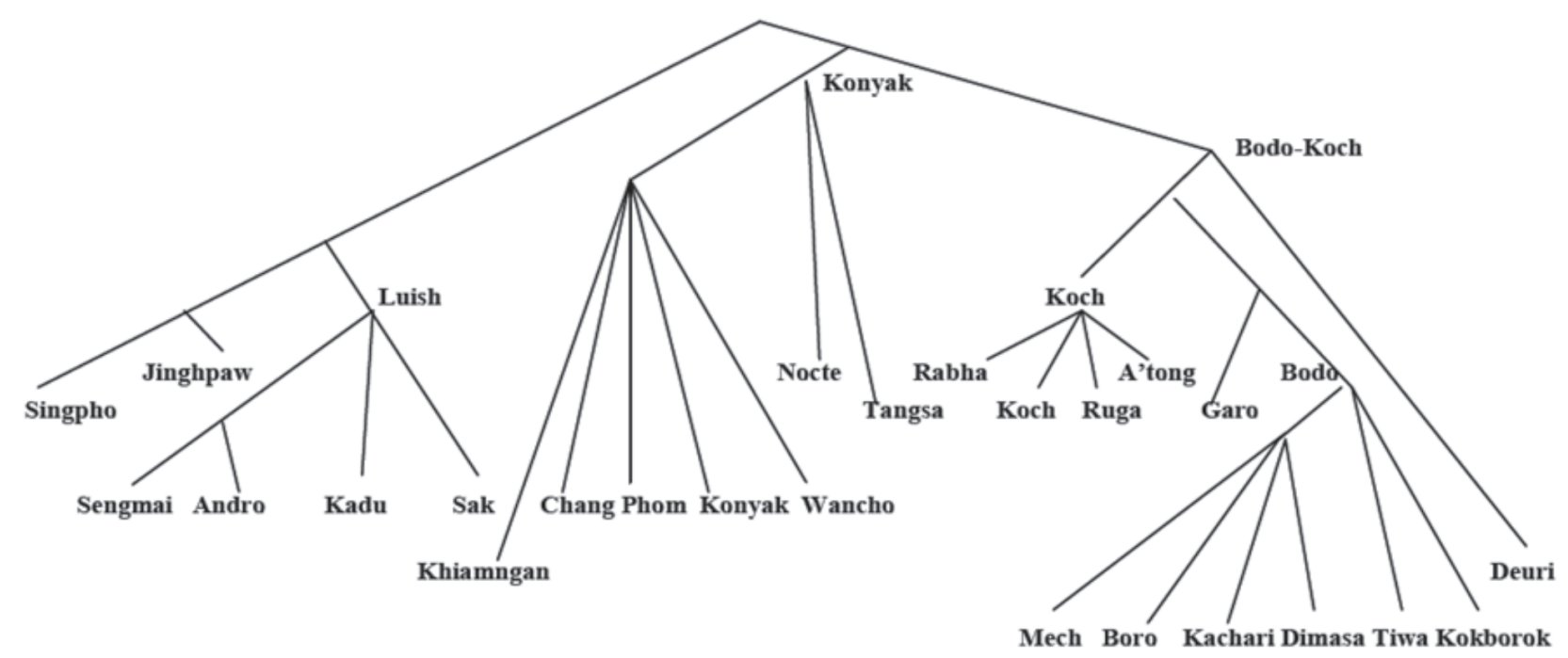

Fig. 8 
and Pani Koch spoken in the western part of the Garo hills) cannot be considered as 'Garo'. He also rejects the term 'Garo of Jalpaiguri' put forth by Grierson (1903). This group of language speakers call themselves 'Koch' or 'Rabha' which Burling finds acceptable. The Bodo sub group includes languages like Mech, Dimasa, Kachari, Tiwa (Lalung) spoken in Assam, Kokborok spoken in Tripura and Deori/Chutiya spoken in eastern part of Assam. Garo which is spoken in the western part of Meghalaya and in the neighboring areas of Assam and Bangladesh, is considered as a separate branch under Bodo-Koch.

Burling (2003) classifies the Konyak group depending upon the linguistic unity which he considers to be relatively clear. The six languages - Tangsa, Nocte, Wancho, Konyak, Phom and Chang are identified as belonging to the Konyak group. Khiamngan is a late addition to this group. Tangsa and Nocte are found to form a sub-group within the Konyak group due to the convincing evidence regarding their closeness provided by earlier scholarship. Burling observes the languages of the Konyak group as quite heterogeneous and that the 'dialects' lack mutual intelligibility. He considers Jinghpaw (mostly spoken in Myanmar and Yunnan) as a sub-group of the Tibeto-Burman group due to its linguistic similarities with Bodo-Koch and Konyak group. Burling (2003, p.178) citing Benedict (1976, p.178) considers the similarities of Jinghpaw with Bodo-Koch and Konyak to be older though Jinghpaw is spoken in an area which is geographically remote from Bodo-Koch and Konyak group of languages. Geographically, a form of Jinghpaw known as 'Singpho' which is spoken in Arunachal Pradesh is closer to Tangsa (the northern most language of the Konyak group) speaking area. A 'bit less similar' factor between Jinghpaw with Bodo-Koch and Konyak is considered to be the influencing factor behind the classification provided by Burling (2003). Benedict (1972, p.5) points out the similarities between a group of minor languages known as 'Luish' with that of Jinghpaw. Luish sub-group is represented by Andro and Sengmai (spoken in Manipur) and Sak (spoken in Chittagong Hill tracks of Bangladesh) and Kadu (spoken in upper Burma) are found to be closely related to Jinghpaw (an observation developed from a modest data of mainly of wordlist). Depending both upon the linguistic and geographical criteria Burling (2003, p.178) presumes that,

$$
\begin{aligned}
& \text { "... the Bodo-Koch languages once had } \\
& \text { a more continuous distribution than they } \\
& \text { do now, but that they have been separated } \\
& \text { by the gradual spread of the Indic } \\
& \text { languages. It seems probable that the } \\
& \text { earlier forms of Bodo-Koch were, at one } \\
& \text { time, the predominant languages of the } \\
& \text { Assam valley and perhaps of some parts } \\
& \text { of northern Bengal as well." }
\end{aligned}
$$

Regarding the languages of the Northern Area Burling (2003) particularly concentrates on the Tibeto-Burman languages spoken in Arunachal Pradesh. He provides us with the geographical location of these languages and discusses about the different names of these languages at different geo-political settings. The observation of Burling (2003) regarding the existence of the same language spoken across the borders in the countries like Bhutan, China, Myanmar and Tibet helps us to understand the genetic and areal relationship of these languages. For instance, Tshangla which is spoken in the western part of Arunachal Pradesh is also spoken in south-eastern Bhutan in the name 'Sharchopkha' and in the name of 'Cangluo Memba' in China. Takpa which is spoken in the western tip of Arunachal Pradesh is also spoken in Tibet in the name 'Cuona Menba' (Michailovsky and Mazaudon, 1994; Van Driem, 1992, p.11). Due to the close resemblance observed from the comparative study of the vocabulary of Tshangla and Takpa and their marked difference from other languages of Arunachal Pradesh (except some scattered resemblances with Sherdukpen) Burling groups 
Tshangla and Takpa together. Sherdukpen, Bugun/ Khoa, Sulung and Lishpa have been grouped together due to their similarities studied at the vocabulary level, which is remarkably different from other Tibeto-Burman languages. Hruso (Aka) and Dhanmai/Miji which Shafer (1947) termed as 'Hruso B' and 'Hruso A' respectively, are clubbed under one group called 'Hruish'. The lesser known Bangru/ Levai (spoken along the Tibet border) is added as a third language to this Hruish group depending upon the similarities at the vocabulary level.

Following Sun (1993) the languages spoken in the central Arunachal Pradesh like 'Abor', 'Miri', 'Dafla' have been grouped by the term 'Tani' by Burling (2003, p.181). The Tani group includes Mirish, Misingish, Abor, Miri and Nishi (also known as Dafla). The Stambaum of Tani group provided in Burling (2003, p.181) is given below in Fig. 9.

Burling (2003, p.180) significantly observes that, "The membership of the Tani group is clear, but the internal relationships amongst its languages have been muddled by an ethnic classification that is only vaguely related to the language classification." The two other groups of the northern area are Idu-Digaru and Miju, the classification of which is based on the lexico- statistical comparative account provided by Sun (1993, p.160). The confusion between the ethnic identity and the classification based on linguistic characteristics is difficult to be resolved due to lack of extensive linguistic surveys of the languages.

The Tibeto-Burman languages of the Eastern border area of North-East India attest high linguistic heterogeneity. These languages are classified under Mizo-Kuki-Chin by Burling. These languages were classified by Shafer as 'Nāgà'. Depending upon lexical comparison Burling (2003, p.184) classifies the languages of the eastern border region (Nagaland, Manipur, Mizoram) with nomenclature based on the prominent languages. These are presented in the following.

(1) Ao-group (2) Angami-Pochuri group (3) Zeme group (4) Tangkhul group (5) Karbi (Mikir) (6) Meithei and (7) Mizo-Kuki-Chin (Kukish) Group

To the Ao-group belongs Yacham-Tengsa, Ao-Chungli and Ao-Mongsen - the last two being relatively close to each other. The other languages of this group are Sangtam, Yimchungru and Lotha. It is significant to mention here that Lepcha (spoken in Sikkim and in northern part of West

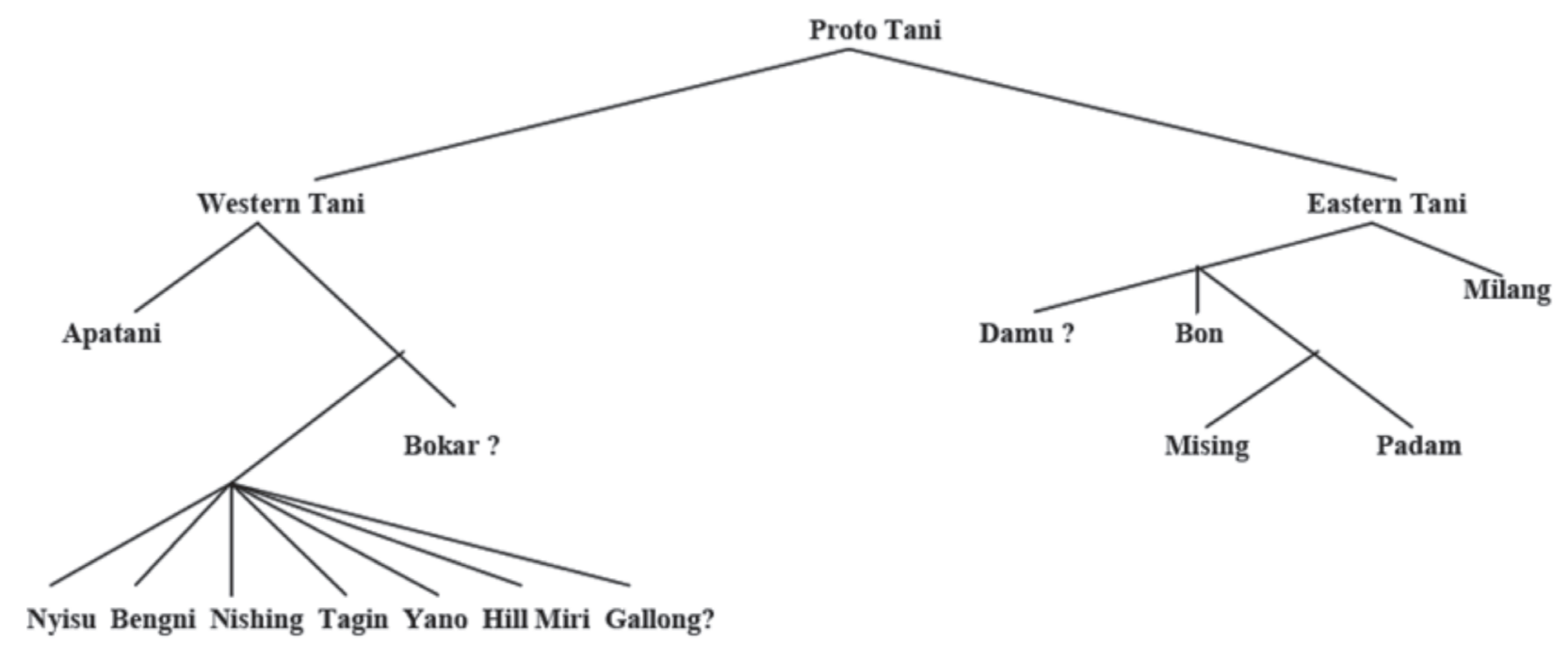

Fig. 9 
Bengal) is considered as belonging to the Ao group by Shafer (1955, p.106) mainly due to its resemblance with Tengsa numerals. However, Burling (2003) keeps the issue outside the purview of his discussion as it lies outside the geographical range. The Angami-Pochuri group due to their closeness at the lexical level includes the languages like Rengma-North, Pochuri, Rengma, Simi, Angami, Chokri, Kheza and Mao (Burling, 2003, p.184).

The Zeme group includes Nruanghmei, Puiron, Khoirao, Zeme, Mzieme, Liangmai and Maram. The Tangkhul and Maring languages spoken in Manipur have been grouped under Tangkhul group by Burling (2003, p. 184). Burling following Shafer prefers to consider Karbi (also called Arleng) (spoken in Karbi-Anglong hills of Assam) in a separate category in spite of its resemblance with Mizo-Kuki, but the resemblance was not found enough to consider it with MizoKuki-Chin group.

'Meitei' or 'Meiteilon' is a developed Tibeto-Burman language which exhibit resemblance at the lexical level with Kuki and Tangkhul. Burling (2003, p.187) explains the reasons for resemblance of these languages by stating,

\footnotetext{
"This could be the result of borrowing from the language of the politically and culturally dominant Meitei, and the resemblances are not great enough to make the assignment of Meitei to one of the groups obvious."
}

The Mizo, Kuki and Chin languages which Burling says 'Kukish' form a separate sub-group. The language which is known as 'Kuki' in India is called 'Chin' in Myanmar. The reason for this is traced in the colonial period of India when the British administrators adopted the nomenclature 'Chin' from its neighboring speech communities of the area. Burling mentions a number of speech communities like Aimol, Anal, Chiru, Chotha, Gangte, Hmar, Kom, Lakher/Mara, Paite, Pawi,
Ralte, Thado, Vaipe by which Kuki speakers are known in the North-East region of India.

\section{Conclusion}

It has been pointed out by the scholars that there has taken place a change in the attitude of the people after independence regarding using their indigenous names instead of those given by the British administrators. This has been observed by Burling (2003, p.171) by stating, "Since independence more and more people have insisted upon using their own names or have even invented new names. The people formerly known as 'Lushai' are now called 'Mizos'. The 'Mikir' have become 'Karbi', the Plains 'Miri', 'Mising'. Some people have also realigned their ethnic affiliation.... Such realignments mean that it is not simply the names of stable groups that change, but also the groups that need to be named." The inappropriateness of the term 'Kamarupan', a term which was used by Matisoff (1991) was also discussed by Burling (2003, p.172) “... simply as a convenient geographical catch all in which to toss these north eastern languages when their genetic sub-grouping was unclear.” Burling (2003, p.172) while discussing the issue rightly points out that, "There is not a shred of evidence for any special genetic relatedness of all the North-eastern Indian Tibeto-Burman languages, and ample evidence against such grouping." Therefore, he suggests abandoning the terms like 'Kamarupan' and also the term 'Nāgā' as it does not indicate any 'Linguistic unity'.

An assessment of the characterization and classification of the Tibeto-Burman languages spoken in the North-East region of India, provided by the scholars during the last two centuries can be said to be essentially based on the lexicostatistical analysis (except that which is provided by Marrison 1967). Taking cue from Burling (2003) the nature and extent of the scientific enquiry of the Tibeto-Burman languages have been summarized as follows: 
(1) As the scientific enquiry of the languages of North-East India was restricted to the vocabulary level in the early part of the nineteenth century, the influence of the language/ s of the super-stratum (having areal influence, especially at the lexical level) hindered the identification and proper characterization of the lesser known languages of the region. (2) Due to lack of proper identification of the cognates, classification of the speech variety (as to whether it is a separate language or a variation (dialect) of a language) suffered from limitation. (3) As a result co-relation between the geographical location and the linguistic identification could not be established objectively. (4) Due to ever volatile socio-political situation of the region co-ordination between ethnic affiliation and linguistic characterization suffered limitation. (5) It was by the end of the nineteenth century, the scientific enquiries of the languages especially at the morpho-phonological level (a relatively more subtle study of the structure of the speech sounds) became a desideratum in order to characterize and classify the languages with more objectivity.

The scientific enquiry of the TibetoBurman languages which started in the latter part of the eighteenth century and carried out throughout nineteenth and twentieth century and also in the first decade of the twenty first century reveals the fact that the rationale behind the classification of this language sub-family is primarily geographical. The linguistic aspect which was mingled with this is by and large the shared morphological characteristics of the languages excavated by employing comparative philological approach restricted to the vocabulary level. The perspective changed with the shift in the focus from morphological to morphophonological aspect. The geographical criteria continued to be the factor behind the classification of these languages, though the classification of Nāgā languages provided by Marrison (1967) is based on a typological study keeping in view the phonological, morphological and syntactic comparisons. For example, depending upon the typological criteria Marrison (1967) considered Rengma as a language of the Zeme group but keeping in view the closeness at the lexical level Rengma was considered a language under Angami-Pochuri group in Burling (2003). The classification of 'Nāgā -Bodo' and 'Nāgā-Kuki' provided by Grierson (1903-1927) is mainly based upon the geographical proximity of these languages and not on linguistic criteria. But later Burling (2003) considered these languages (like Nruanghmei, Puiron, Khoirao, Zeme, Mzieme, Liangmai and Maram) as belonging to the Zeme group, the criteria being linguistic. Grierson's characterization and the classification (though essentially dealt with morphology) is solely based on data collected from field investigation. No doubt with the increase in the linguistic analyses (descriptive/ typological grammar) of more languages in the latter part of the twentieth century the reliance on the linguistic (i.e., phonological and morpho-phonological) criteria behind the classification of the Tibeto-Burman languages gained ground but geographical criteria continued to play a crucial role in the scientific linguistic enquiry of these languages evident even in the first decade of the twenty first century.

Therefore, the trend of the scientific enquiry reiterates the fact that the impact of space by means of contact and the impact of time revealed through the study of changing structures ('linguistic structure' in this case) are the inseparable phenomena in realizing the conscious existence. "In relation to the evident, necessary, universal order introduced into representation by science, and by algebra in particular, language is spontaneous and un-thought-out; it is, as it were, natural. It is equally, according to the point of view from which one looks at it, an already analyzed representation and a reflection in the primitive state. In fact, it is the concrete link between representation and reflection. It is not so much 
the instrument of men's intercommunication as the path by which, necessarily, representation communicates with reflection. This is why general grammar assumed so much importance for philosophy during the eighteenth century; it was, at one and the same time, the spontaneous form of science - a kind of logic not controlled by mind
- and the first reflexive decomposition of thought: one of the most primitive breaks with the immediate. ...Language is the original form of all reflection, the primary theme of any critique. It is this ambiguous thing, as broad as knowledge, yet always interior to representation, that general grammar takes as its object" (Foucault, 2002, p. 92).

\section{AppendiX-1}

The interrelationship between the major groups and the sub-groups have been identified in Shafer(1974) by using '-ic' for main divisions of a family (e.g., Sinitic, Burmeic, etc.), '-ish' for section of a main division (e.g., Burmish, Kukish, etc.). The classification of Sino-Tibetan provided in Shafer (1974) is presented below.

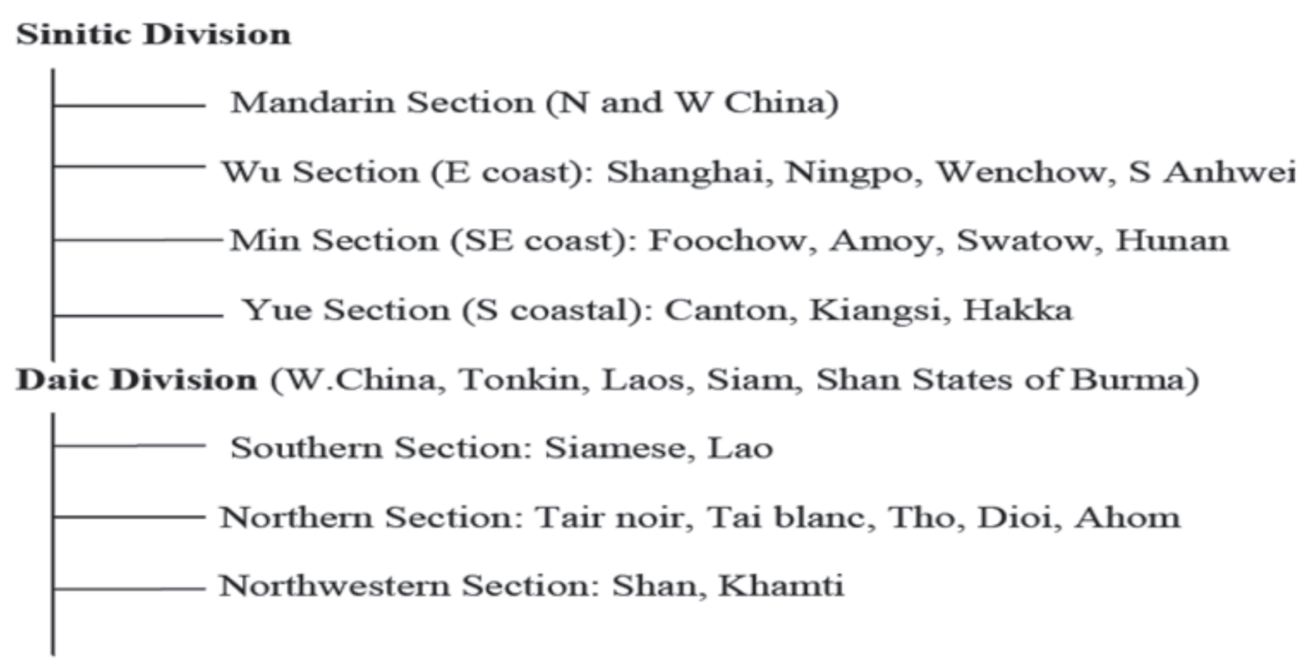




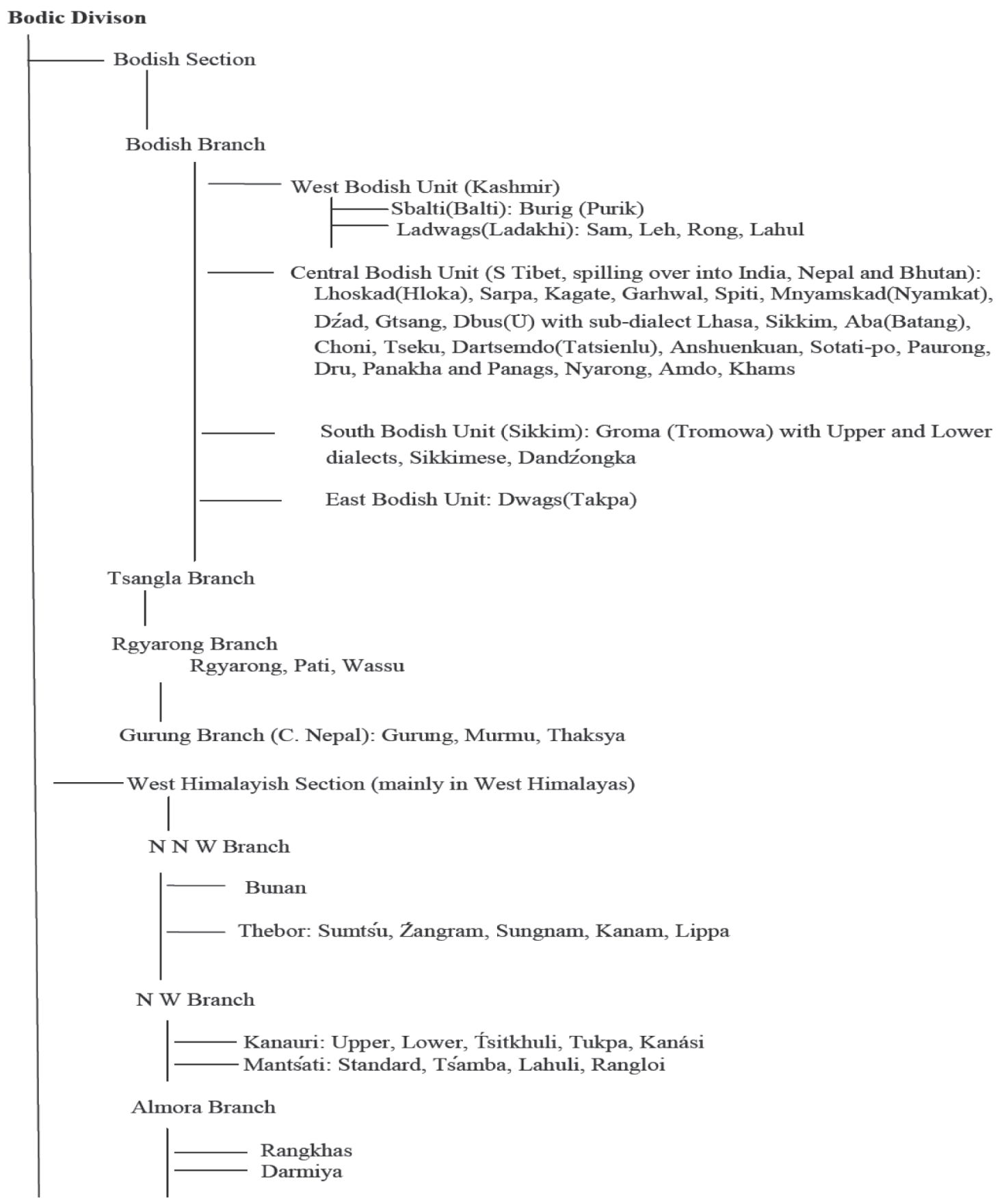




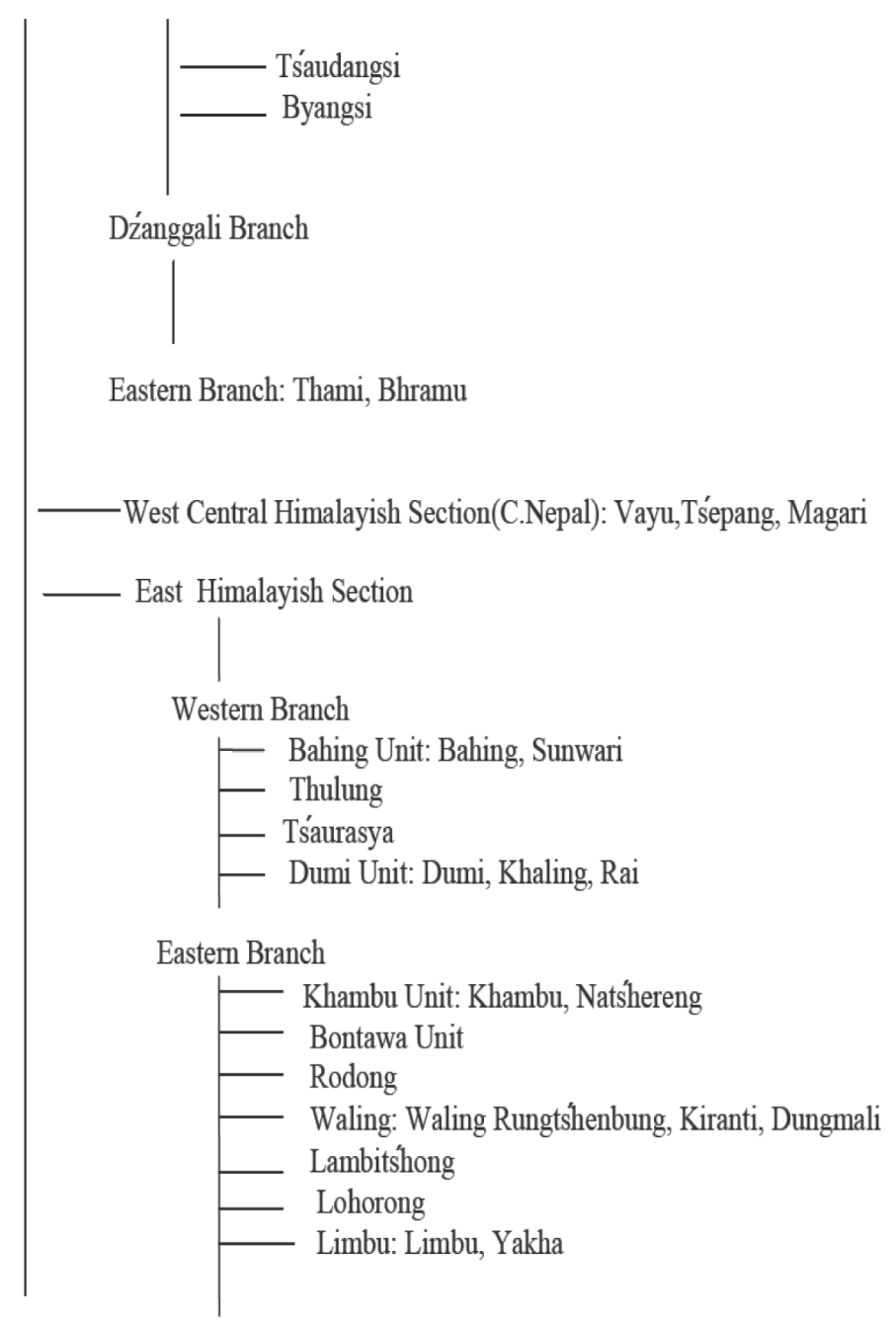

There are languages which are not classified under a division. These are referred as 'probably sections of Bodic' and 'possibly of Burmic'. They are---

Newarish (C. Nepal): Newari, Pahri

Degarish (NE Assam and into Tibet)

Midźuish (In Tibet beyond NE Assam)

Hruish (N Assam): Hruso (Aka), dialects of A and B

Dhimalish (Darjeeling and Jalpaiguri): Dhimal, Toto

Miśngish (NE Assam and into Tibet)

Mising (Miri)

Abor

Yano

Nyising (Dafla)

E

C

Tagen

Apa Tanang 
Dzorgaish (Dzorgaic?) (NE Tibetan plateau and Szechuan, Kansu): Thotśu, Dzorgai, Kortse,

"Outer Mantse", Pingfang, Ch'iang

\section{Burmic division}

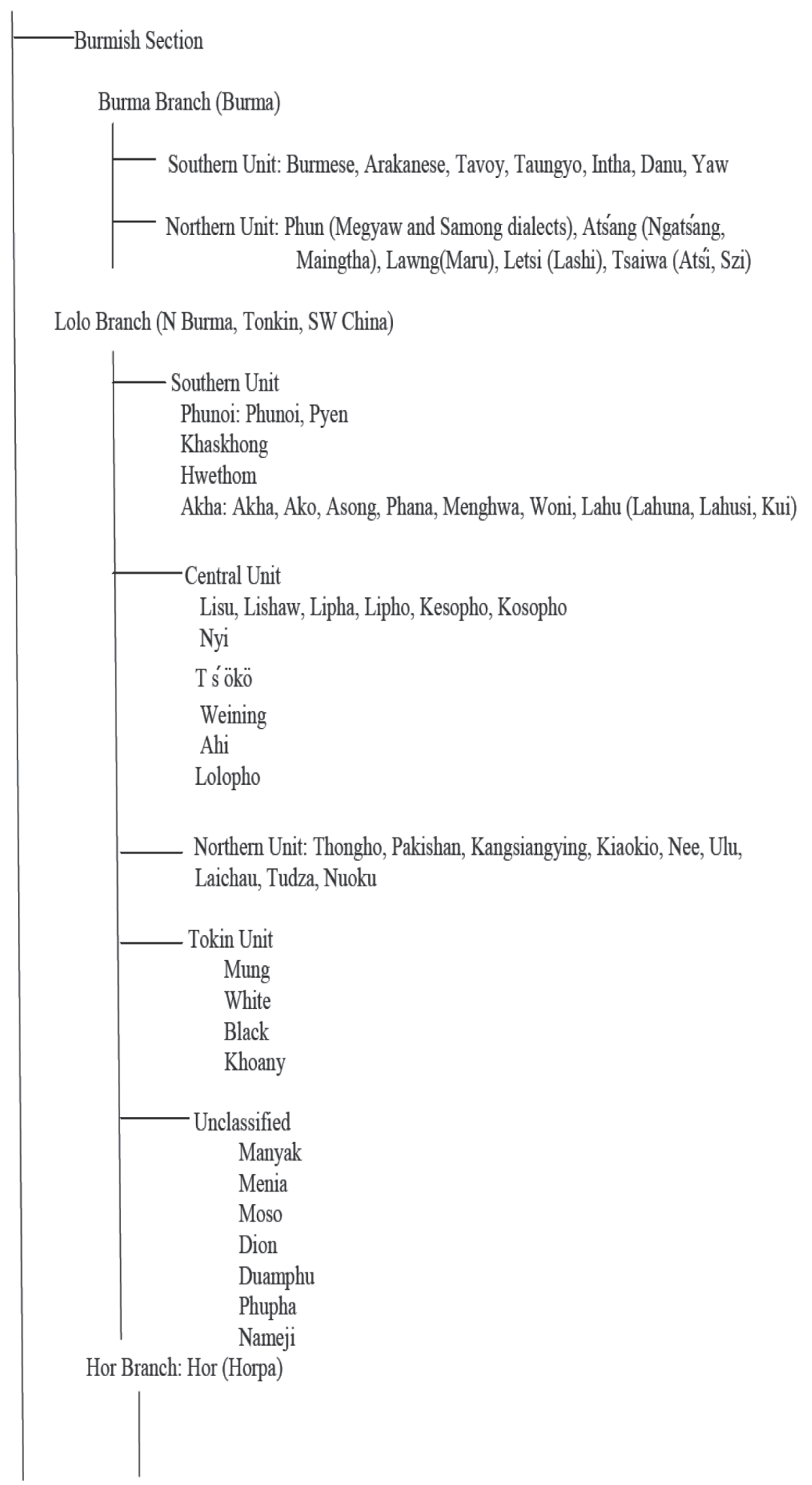



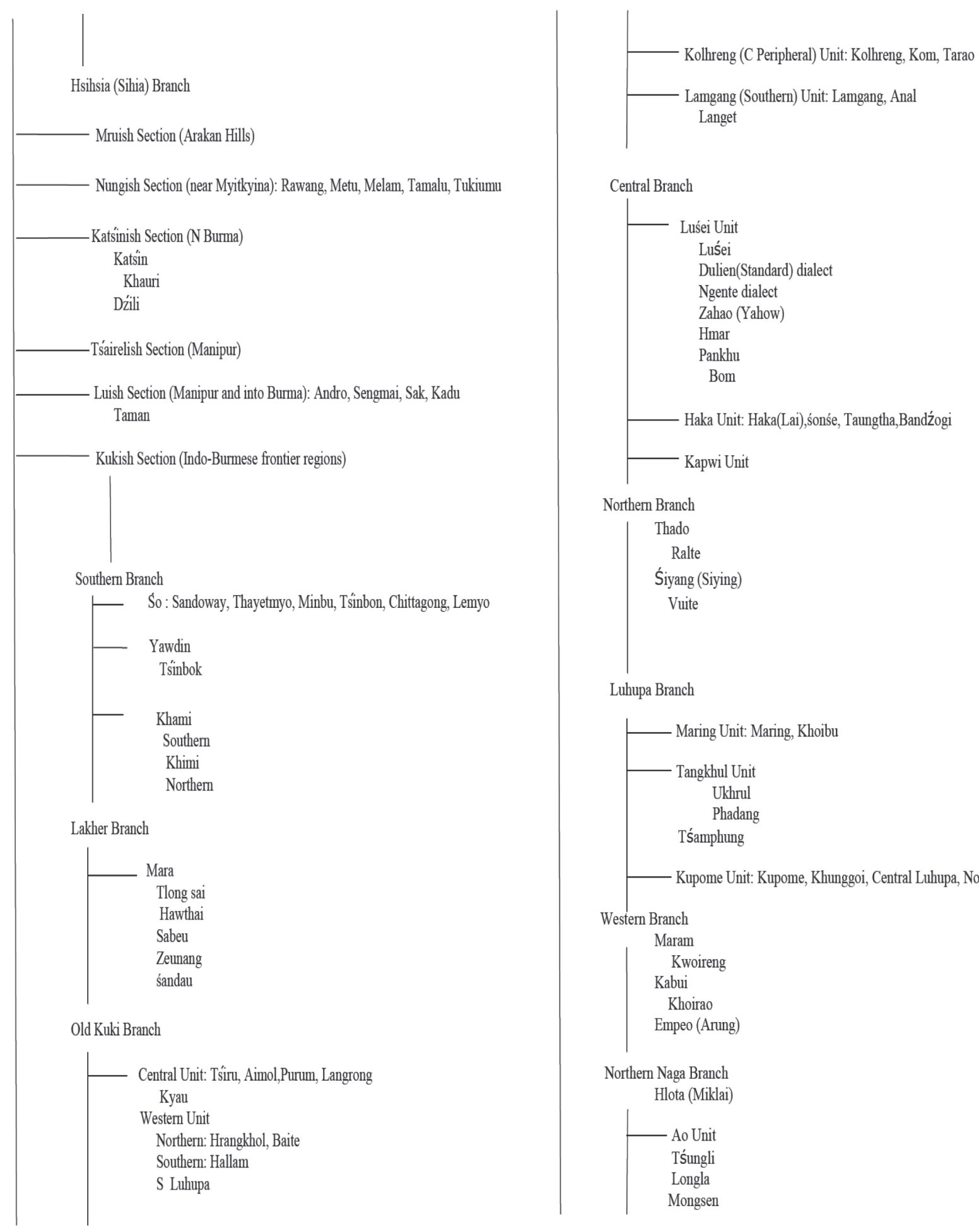

Northern Branch

Thado

Ralte

Śiyang (Siying)

Vuite

Luhupa Branch

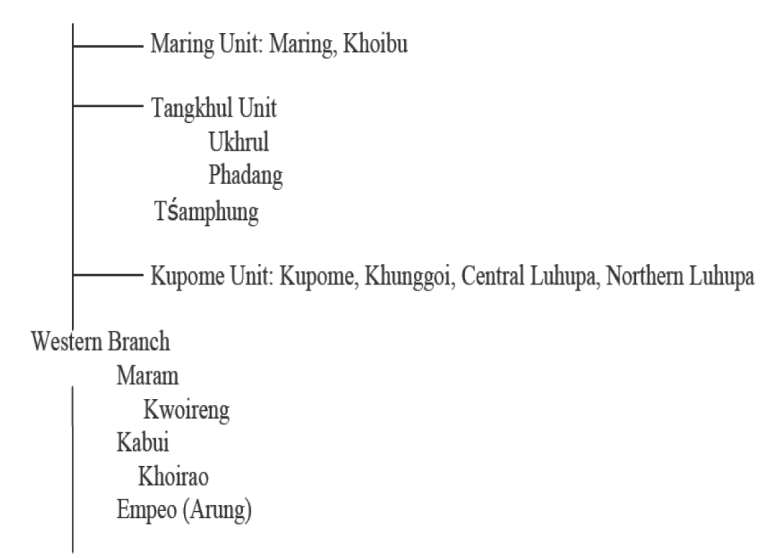

Northern Naga Branch

Hlota (Miklai)

_ Ao Unit

Tśungli

Longla

Mongsen 


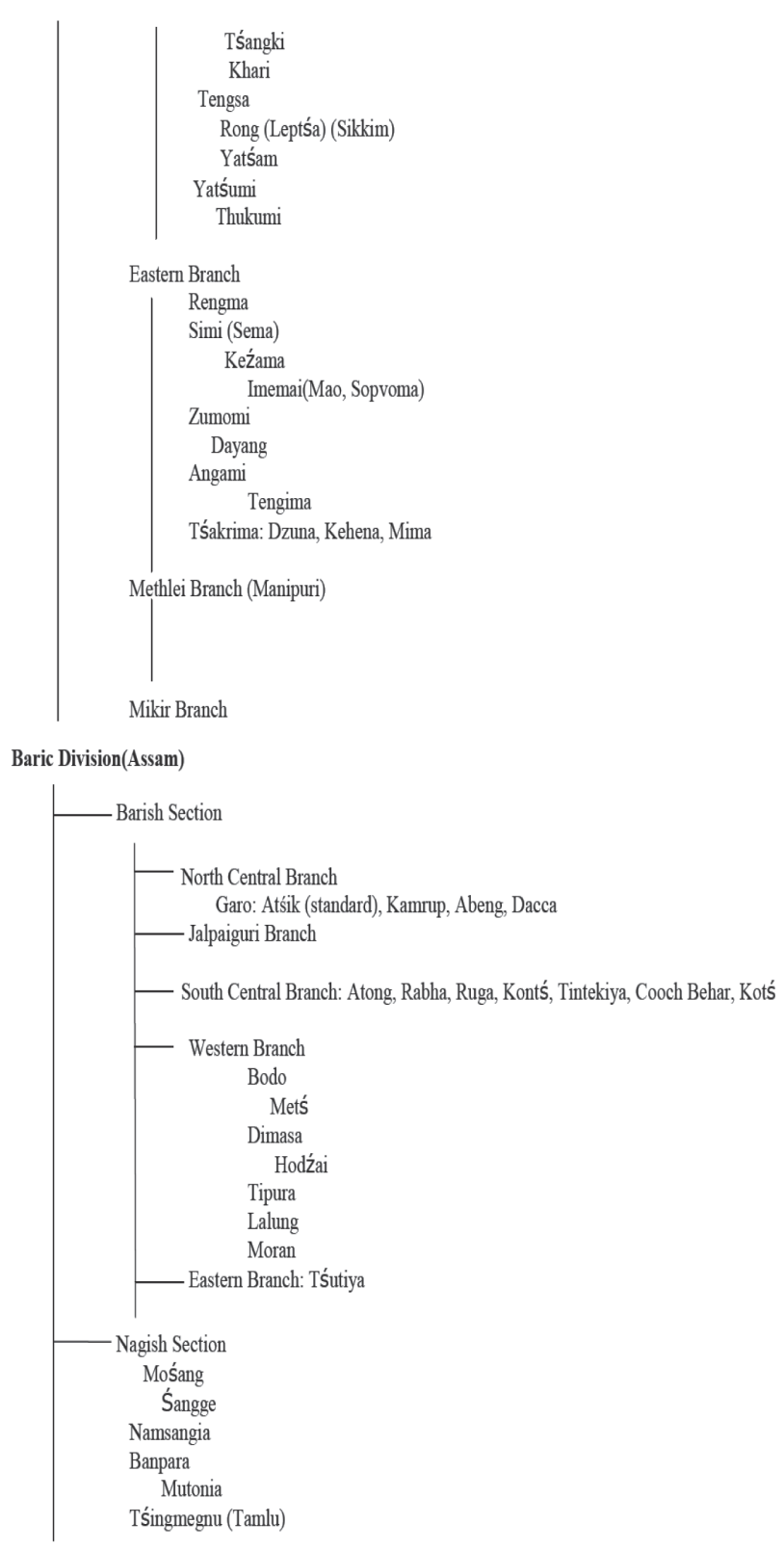

\section{ACKNOWLEDGEMENT}

I am extremely grateful to Indian National Science Academy, New Delhi for sanctioning me a project on linguistic historiography of NorthEast India, the present paper being an outcome of the first phase of investigation of the research program.

\section{BiBLIOGRAPHY}

Beams, John. A Comparative Grammar of the Modern Aryan Languages of India, Mushiram Monoharlal, New Delhi, 1872-79, Reprinted 1970.

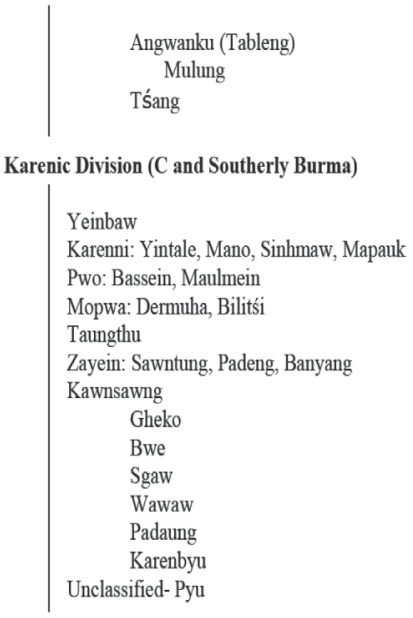

Benedict, Paul K. Sino-Tibetan:A Conspectus, Cambridge University Press, London, Cambridge, Matisoff, James A. (ed.), 1972.

Benedict,Paul K. Sino-Tibetan: another look, Journal of the American Oriental Society, 96.2 (1976) :167-197.

Bradley, David. Tibeto-Burman languages and classification, in: Bradley, David (ed.), Tibeto-Burman languages of the Himalayas, Papers in South East Asian linguistics 14, Canberra: Pacific Linguistics, 1997, pp. 1-71.

Bradley, David. The Subgrouping of Tibeto-Burman, in: Beckwith, Chris; Blezer, Henk, Medieval TibetoBurman languages, BRILL, 2002, pp. 73-112.

Burling, Robins. The Sal Languages, Linguistics of the Tibeto-Burman area, 7(2) (1983): 1-32.

Burling, Robins. The Tibeto-Burman Languages of NorthEast India, in: Graham Thurgood \& Randy LaPolla (ed.) The Sino-Tibetan Languages, Routledge, London and New York, 2003, pp. 169-191.

Campbell, Sir Colin. Specimen of the languages of India, including those of the aboriginal tribes of Bengal, the central provinces and the Eastern Frontier (Khasi vocabulary on pp. 220, 272) Calcutta, 1874.

Chatterji,Suniti Kumar. Kirāta-Jana-K[ti ,The IndoMongoloids: Their Contribution to the History and Culture of India, The Asiatic Society, Kolkata, 1951.

Conrady, August. Eine Indo-Chinesische CausativeDenominativ-Bildung und ihr Zusammenhang mit den Tonaccenten, 1896.

Dalton, Edward Tuite. Descriptive Ethnology of Bengal, Calcutta, 1872.

Damant, Gordon H. Notes on the Locality and Population of the Tribes dwelling between Brahmaputra and Ningthi Rivers, in: www. linguistics. berkley. edu/ dwbruhn/ STEDT/ Damant 1880 notes tribees.pdf. (Retrieved on 03.06.2016), 1880. 
Driem, George Van. The Grammar of Dzongkha, Dzongkha Development Commission, Royal Government of Bhutan, 1992.

Forbes, Charles James. On Tibeto-Burman languages, Journal of the Royal Asiatic Society of Great Britain and Ireland, New Series X(1878): 210-227.

Foucault, Michel. The Order of Things: An archaeology of the human sciences, Routledge Classics, London and New York, 2002, First published in 1966.

Grierson,George Abraham. Linguistic Survey of India, Motilal Banarasidass, Delhi Varanasi Patna, Vol.II, 1903.

Grierson, George Abraham. Linguistic Survey of India, Motilal Banarasidass, Delhi Varanasi Patna, Vol.III, Pt.II, 1908, pp. 49-55.

Grierson,George Abraham. Linguistic Survey of India, Motilal Banarasidass, Delhi Varanasi Patna, Vol.I, Pt.I., 1927.

Grube, Wilhelm. Die sprachgeschichtliche Stellung des Chinesischen, Leipzig, 1881.

Hodgson, Brian Houghton. Comparative Vocabulary of The Several Languages or Dialects of the Eastern SubHimalayas, From The Kali or Ghogra to The Dhansri, with the Written and Spoken Tibetan Comparison, Journal of the Asiatic Society, XVI(1847): 1245-1246.

Hodgson, Brian Houghton. On the Aborigines of NorEastern India, Journal of the Asiatic Society, 18(1849): 451-460.

Hoernele, Rudolf. A Comparative Grammar of the Gaudian Languages, London, 1880.

Hunter, William Wilson. A Comparative Dictionary of the Languages of India and High Asia, Cosmo Publication, New Delhi, 1888, Reprint 1975.

Klaproth, Julius. Asia Polyglotta, B.A. Shubart, Paris, 1823.

Kuhn, Ernest. Über Herkunft und Sprache der transgangetischen Volker, Verlag d. k. b. Akademie, Munich, 1883.

Lacouperie, Teerrien de. Languages of China Before the Chinese, London, 1887.

Li, Fang-kuei. Languages and Dialects, The Chinese Year Book, 1936-37,pp. 121-128.

Logan, James Richardson. The West-Himalaic or Tibetan tribes of Assam, Burma and Pegu, Journal of the Indian Archipelago and Eastern Asia, 2 (1) (1858): 68-114.

Marrison, Geoffrey Edward. The Classification of the Naga Languages of North-East India, Unpublished Ph.D dissertation, School of Oriental and African Studies, University of London, 1967.

Matisoff, James A. Sino-Tibetan Linguistics: Present State and Future Prospects, Annual Review of Anthropology 20(1991): 469-504.
Michailovsky, Boyd and Mazaudon, Martine. Preliminary notes on the languages of Bumthang group, Tibetan Studies, Proceedings of the $6^{\text {th }}$ Seminar of the International Association for Tibetan Studies, The Institute for Comparative Research in Human Culture, Oslo, 1994.

Müller, Friedrich Max. Languages of the seat of war in the East, with a survey of the Three Families of Languages, Semitic, Arian, and Turanian (frontispiece title: Max Müller's Survey of Languages, $2^{\text {nd }}$ edn.) Williams and Norgate, London, 1855.

Nigam, Ramesh Chandra. Census of India 1961. Vol.I. Part II-C(ii). Registrar General and ex-officio Census Commissioner for India, 1961.

Przyluski, Jean. Le Sino-tibétain [and] Les Langues austroasiatiques, in: A. Meillet and M. Cohen (ed.), Les Langues du Monde. Librairie Ancienne edouard Champion, Paris, 1924, pp. 361-384 [and] 385-403.

Robinson,William. Notes on the languages spoken by the various tribes inhabiting the valley of Assam and its mountain confines, Journal of the Asiatic Society, XVIII (1849):183-235.

Schmidt, Pater Wilhelm. Die Sprachfamilien und Sprachkreise der Erde, Heidelberg, 1926.

Shafer, Robert. Hruso, Bulletin of the School of Oriental and African Studies, 12(1947):184-196.

Shafer, Robert. Classification of the Sino-Tibetan Languages, Word 11(1955):94-111.

Shafer, Robert. Introduction to Sino-Tibetan. Part I-V, Wiesbaden: Otto Harrassowitz, Germany,1966-1974.

Shafer, Robert. Introduction to Sino-Tibetan. Germany: Otto Harrassowitz . Wiesbaden, 1974

Skrefsrud, Lars Olsen. A Short Grammar on the Mech or Boro Language, Calcutta School Book Society, Calcutta, 1889.

Sun, JacksonTian- Shin. The Linguistic Position of Tani (Mirish) in Tibeto-Burman: A Lexical Assessment, Linguistics of the Tibeto-Burman Area, 16(2) (1993):143-188.

Thurgood,Graham. A Subgrouping of the Sino-Tibetan Languages: The Interaction between Language Contact, Change, and Inheritance, in: G. Thurgood \& R. LaPolla (ed.), The Sino-Tibetan Languages, Routledge, London and New York, 2003.

Trombetti, Alfredo. Elementi di Glottologia, 2 vols, Zanichelli, Bologna, 1923.

Van Driem, George. The Grammar of Dzongkha, Dzongkha Development Commission, Royal Government of Bhutan, Bhutan, 1992.

Wolfenden, Stuart N. Outlines of Tibeto-Burman Linguistic Morphology, Royal Asiatic Society, London, 1929. 